\title{
Catalysis

\section{Catalysis engineering of bifunctional solids for the one-step synthesis of liquid fuels from \\ syngas: a review}

Cite this: Catal. Sci. Technol., 2014, 4, 893

Received 5th December 2013, Accepted 7th January 2014

DOI: 10.1039/c3cy01021j

www.rsc.org/catalysis

\author{
Sina Sartipi, ${ }^{*}$ Michiel Makkee, Freek Kapteijn and Jorge Gascon*
}

\begin{abstract}
The combination of acidic zeolites and Fischer-Tropsch synthesis (FTS) catalysts for one-step production of liquid fuels from syngas is critically reviewed. Bifunctional systems are classified by the proximity between FTS and acid functionalities on three levels: reactor, catalyst particle, and active phase. A thorough analysis of the published literature on this topic reveals that efficiency in the production of liquid fuels correlates well with the proximity of FTS and acid sites. Moreover, possible side reactions over the FTS metal, including direct $\mathrm{CO}$ hydrogenation and hydrocarbon hydrogenolysis, are addressed. The contribution of these side reactions should carefully be considered and separated from that of the zeolite function when evaluating the performance and product spectrum of zeolite-containing catalysts.
\end{abstract}

\section{Introduction}

Due to their high volumetric and reasonable mass energy densities and low cost/price, gasoline and diesel are the preferred transportation fuels. To date, these liquid fuels are being mainly produced in conventional refineries from crude oil. Depletion of petroleum and environmental concerns have

Catalysis Engineering, Department of Chemical Engineering, Delft University of Technology, Julianalaan 136, 2628 BL Delft, The Netherlands. E-mail: S.Sartipi@tudelft.nl, J.Gascon@tudelft.nl; Fax: +31 15 2785006; Tel: +31152786733

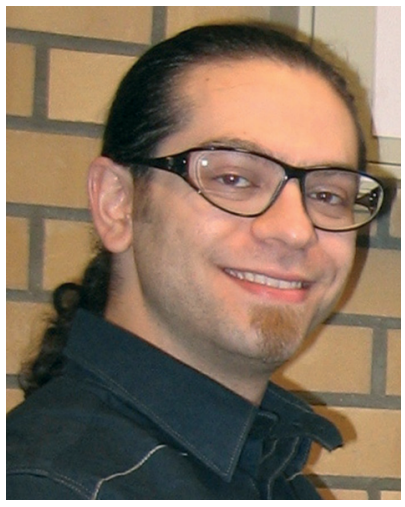

Sina Sartipi
Sina Sartipi (1981) is a chemical engineer, specialized in the field of heterogeneous catalysis. After obtaining his MSc from the University of Tehran (Iran), he did his PhD at Delft University of Technology (Netherlands, 2014). Currently, he is a postdoctoral researcher at Delft University of Technology and the highlighted research topics that he is involved in include heterogenization of hydroformylation catalysts, utilization of metal organic frameworks (MOFs) for heterogeneous catalysis and development of Fischer-Tropsch synthesis catalysts. The latter was the main area of his PhD research as well. He has co-authored nine peer reviewed articles. driven a worldwide research on alternative processes for the production of energy carriers. Among the various possibilities and chemical conversion routes, syngas (a mixture of $\mathrm{CO}$ and $\mathrm{H}_{2}$ ) production followed by Fischer-Tropsch synthesis (FTS) holds promises for extensive implementation in the near future. This is due to the maturity of both technologies in addition to abundance of alternative resources such as natural gas, coal, and biomass. Furthermore, the dependency on centralized fossil-based reservoirs may be relaxed if globally dispersed raw materials can be utilized as feedstock.

When producing liquid fuels by the state of the art gas-toliquid (GTL) processes, low-temperature Fischer-Tropsch (LTFT)

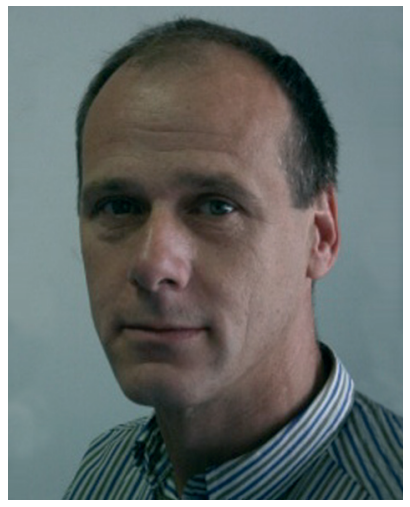

Michiel Makkee
Michiel Makkee (1954) did his master and PhD studies on catalysis and organic chemistry at the Delft University of Technology. After more than 6 years at Exxon Chemicals he was nominated as associate professor in the field of Catalysis Engineering and Process Development at the Delft University of Technology (1990). He was nominated as special part time professor at the Politecnico di Torino (2011). He is (co-)inventor of 25 patents and (co-)author of 200 peer reviewed papers with a H-factor of 44. He lectured in several courses on chemical and reactor engineering and is co-author of the book Chemical Process Technology ( $2^{\text {nd }}$ edition). 
reactors are operated at high chain growth probability conditions at which heavy paraffinic hydrocarbons (wax) are produced with high selectivities. Waxes are subsequently fed to hydrocrackers and converted to the desired cut of the barrel. ${ }^{1}$ Lower hydrocarbon chain growths are expected in processes based on high-temperature Fischer-Tropsch (HTFT) for gasoline production. $^{2}$ Nevertheless, hydrocarbon conversion reactions, including hydroisomerization, are required to upgrade the octane number of the FTS-based gasoline.

Practical feasibility of the conventional GTL should benefit from the so-called 'economy of scale'. ${ }^{3}$ However, process intensification is essential to make use of feedstocks with limited and scattered availability (e.g., renewables) or associated petroleum gas on offshore platforms. The current importance of intensified GTL technologies is illustrated by the number of academic research groups and companies such as CompactGTL, ${ }^{4}$ Velocys, ${ }^{5}$ and Chevron, ${ }^{6}$ currently involved in this research. Yet, it should be stressed that efforts to develop intensified GTL processes do not necessarily aim to substitute the state of the art, already optimized for large scale applications, but are responses to the availability of alternative feedstocks.

From the catalysis engineering prospect, running several reactions by coupling two or more functionalities in a single catalyst particle is a well-known and attractive approach, such as in hydroisomerization. First examples describing the incorporation of additional functionalities in FTS, including water-gas-shift (WGS) and acidity, ${ }^{7}$ have been reported more than two decades ago. ${ }^{8-10}$ The former is intrinsically present in Fe-based FTS catalysts or alternatively can be introduced by addition of a dedicated component such as Cu-based WGS catalysts. ${ }^{10}$ If $\mathrm{H}_{2} / \mathrm{CO}$ ratio is smaller than the reaction stoichiometry (i.e., $\mathrm{H}_{2} / \mathrm{CO}=2$ ), a high $\mathrm{CO}$ conversion may only be achieved in combination with a reasonable extent of in situ

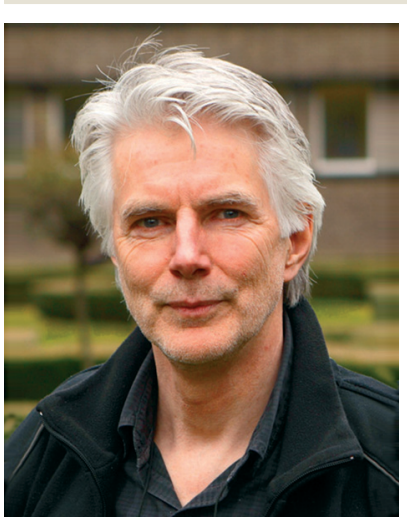

Freek Kapteijn
Freek Kapteijn (1952), MSc in Chemistry and Mathematics, received his $P h D$ on 'Metathesis of alkenes' in 1980 at the University of Amsterdam. After post-doc positions (Coal Science) in Amsterdam and Nancy (ENSIC), he became Associate Professor in Amsterdam. Moved to Delft University of Technology in 1993, received a personal professorship in 1999, and since 2008 he has been section leader of Catalysis Engineering, with visiting professorships at ETH Zürich, Tianjin and Zhejiang Normal University. His research interest focuses on the interplay of catalysis and engineering, comprising structured and multifunctional catalysts, adsorption, separation and (catalytic) membranes. He has co-authored over 400 publications in peer-reviewed journals and book chapters.
WGS. On the other hand, intraparticle $\mathrm{H}_{2} / \mathrm{CO}$ ratios stay closer to the optimal stoichiometric value by feeding $\mathrm{H}_{2}$ deficient syngas, due to the higher diffusivity of $\mathrm{H}_{2} \cdot{ }^{11}$ Therefore, WGS functionality is of high importance, especially when coal or biomass are used as syngas sources with $\mathrm{H}_{2} / \mathrm{CO}$ ratios around unity. ${ }^{12}$

Other active sites have been introduced to add acid functionality to the catalyst. This aims to couple FTS to either etherification $^{13}$ or acid-catalyzed hydrocarbon upgrading (via (hydro)cracking, (hydro)isomerization, etc.). The latter is the subject of this report. While almost a century of literature is available on FTS catalysts, still no new reviews update the recent advances and findings on this topic. ${ }^{12,14-20}$ This contribution is confined to the recent open literature on zeolite-based bifunctional catalyst systems. The possible acidcatalyzed reactions that are likely to occur under FTS conditions are discussed first and their feasibility is assessed (section 2). Following, the possible side reactions at the metal sites, resulting from their interaction with the zeolite, are addressed. These side reactions are consequences of the combination of functionalities, which may affect or alter the product distribution (section 3). On these grounds, the combination of FTS and acid functionalities and their cooperative catalytic performances are discussed in detail as a function of the proximity between both phases, namely on the reactor, catalyst particle, and active phase levels (section 4).

\section{Relevant acid/zeolite catalyzed reactions}

The idea behind the combination of FTS and acid functionalities is the direct production of liquid hydrocarbons from syngas via consecutive CO polymerization and hydrocracking.

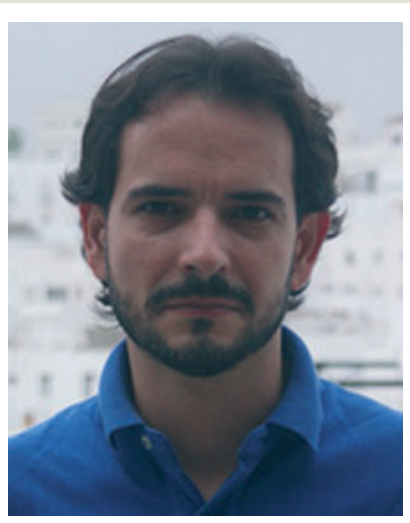

Jorge Gascon
Jorge Gascon (1977) received his MSc in Chemistry in 2002 and his PhD in Chemical Engineering in 2006, both at the University of Zaragoza (Spain). At TUDelft he was post-doc and Assistant Professor. Since 2012 he is Associate Professor of Catalysis Engineering. Research interests include fundamental aspects and applications of new nano-structured materials and composites. He has co-authored over 90 publications, 5 patents and has edited the book: "Metal Organic Frameworks as Heterogeneous Catalysts". He has been the recipient of the prestigious VENI (2010), VIDI (2013) and ERC Starting (2013) personal grants. Recently he received the 2013 ExxonMobil Chemical European Science and Engineering Award. 
In this section, the feasibility of hydrocracking and other acid-catalyzed reactions, likely to occur over bifunctional catalysts, under FTS conditions is discussed.

\subsection{Hydrocracking}

Hydrocracking, catalytic cracking, and thermal cracking are the most important types of cracking. The former two proceed in the presence of a solid catalyst and their main difference is $\mathrm{H}_{2}$ co-feed in the case of hydrocracking. Fluidized catalytic cracking or FCC is a well-known cracking process where no $\mathrm{H}_{2}$ is co-fed to the reactor, operated at 753-823 K. One of the most important components of FCC catalysts is an acidic zeolite. Hydrocrackers on the other hand, are operated in the temperature range of $623-713 \mathrm{~K}^{2}$ At such lower temperatures, incorporation of a (de)hydrogenation function into the catalyst formulation, besides the acidity, is the key to enhance catalyst activity and stability. Conventionally, the (de)hydrogenation function is introduced by a metal, supported on the solid acid catalyst (Table 1).

Hydrocracking catalysts are similar to those of hydroisomerization in the sense that they both contain (de)hydrogenation and acid functionalities. This is due to the fact that reaction intermediates are similar in both reactions: the formation of cracked products is preceded by an isomerization step (see below).
The hydrocracking reaction mechanism is schematically illustrated in Fig. 1 for a representative hydrocarbon. The reaction is initiated by formation of a carbocation. In case of olefins, the carbocation can readily be formed via addition of a proton, supplied by Brønsted acid sites. Otherwise, in the case of saturated hydrocarbons, a dehydrogenation step should precede. Alternatively the olefin may form by abstraction of a hydride ion from the hydrocarbon. The hydride ion can be accepted by the acid catalyst and be combined with a proton to form molecular $\mathrm{H}_{2} \cdot{ }^{21}$

Before C-C scission, the carbocation undergoes skeletal isomerization to form an iso-carbocation.

This proceeds through a secondary carbocation rearrangement, most probably via a protonated dialkylcyclopropane (Fig. 1) for hydrocarbons containing five or more carbon atoms. For C4 hydrocarbons, formation of protonated dialkylcyclopropane is energetically unfavorable since it would call for a primary carbocation as intermediate. ${ }^{23}$

The next mechanistic step of hydrocracking is scission of the $\mathrm{C}-\mathrm{C}$ bond at the $\beta$ position of the positively charged carbon atom ( $\beta$-scission) to form a lighter alkene and a lighter carbocation. The latter may go through a further sequence of reactions as described above or it may be converted to an alkene upon proton abstraction by the acid catalyst. Finally, the olefinic products may adsorb on a metal site and become hydrogenated.

Table 1 Various (de)hydrogenation and acid functions of hydrocracking catalysts. Adapted from ref. 22

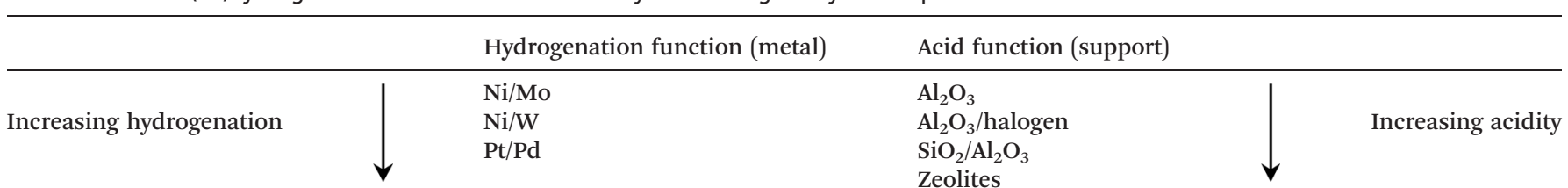

Low sulfur conditions

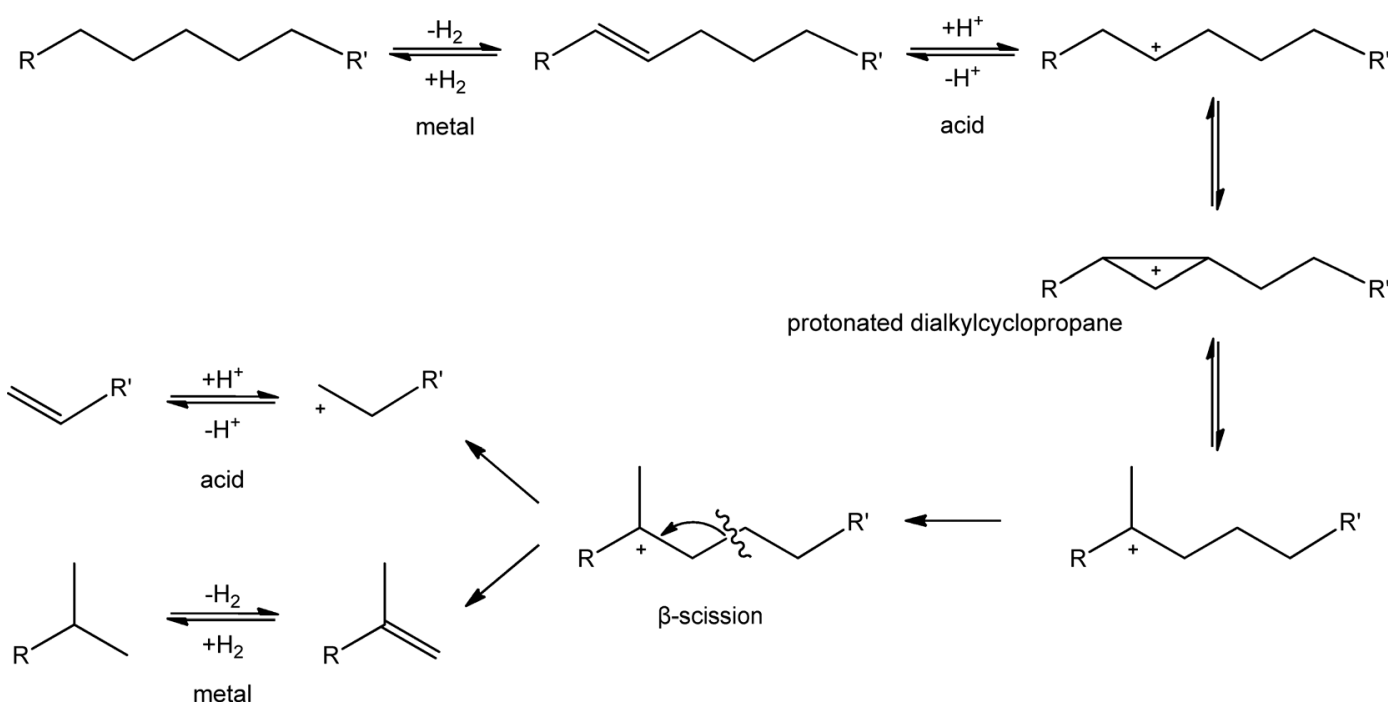

Fig. 1 Hydrocracking reaction mechanism for a representative hydrocarbon. 
A $(n \geq 8)$<smiles>[R]C(C)=CC([R])(C)C</smiles><smiles>[R]C(C)=[C+]C([R])C</smiles>

B2 $(n \geq 7)$<smiles>[R]C1C[C](C([R])C)C1</smiles><smiles>C[C+]CC</smiles><smiles>[R]C(=[CH+])C</smiles>

$\mathrm{D}(n \geq 5)$
$\mathrm{B} 1(n \geq 7)$<smiles>[R]C=C[C+]C([R])C</smiles><smiles>C=[18O]</smiles><smiles>[R]C=[C+]CC[R]</smiles>

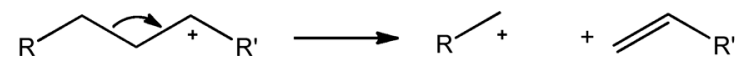

Fig. 2 Examples of different types of $\beta$-scission, imposed to different carbocation intermediates. $n$ : carbon number.

Five types of $\beta$-scission can be distinguished with respect to the stability of the carbocations involved (Fig. 2) for which the relative reaction rates obey the following order: $\mathrm{A} \gg \mathrm{B} 1 \approx$ B2 > C $D^{24}{ }^{24}$ A 'fast' hydrocracking occurs once the hydrocarbon has been hydroisomerized and subsequent branching in the chain leads to fastest hydrocracking. Among the different acid supports employed in hydrocracking catalysts (Table 1), zeolites offer a high stability as well as shape selectivity. Inside shape selective zeolites such as ZSM-5, the branched reaction intermediates are blocked where they undergo successive isomerization steps and rapid cracking. ${ }^{25}$

The above-mentioned reaction steps for hydrocracking are based on a monomolecular mechanism. In the so-called bimolecular mechanism, ${ }^{26-28}$ an alkene is protonated by the Brønsted acid and forms a dimer with another olefinic hydrocarbon (Fig. 3). This oligomerization process may continue and depending on the position of the double bond and the positively charged carbon on the chain, branched carbocations may be produced. The carbocations may further return a proton to the acid catalyst to form an olefin (which is larger than the starting molecules) or they may crack. The bimolecular mechanism seems more feasible than the protonated cyclopropane formation for hydroisomerization and/or hydrocracking of small hydrocarbons (such as $\mathrm{C} 4$ ) that would require primary carbocation intermediates through the latter route. ${ }^{29,30}$

In the absence of a (de)hydrogenation functionality (such as in FCC catalysts), hydrogen is transferred from the hydrocarbon feed to the catalyst surface and distributed over the adsorbed hydrocarbon species. This enriches the $\mathrm{H} / \mathrm{C}$ ratio of a fraction of components (usually the lighter ones) while reducing that of the others (usually the heavier ones) and thus carbon is rejected in the form of coke on the catalyst surface. ${ }^{31}$ In this case, pentacoordinated structures (Fig. 4) are formed by direct protonation of the paraffins which can crack in $\alpha$ position of the positively charged carbon ( $\alpha$-scission, protolysis). Once significant concentrations of alkenes are created, cracking through the aforementioned mechanism(s) and $\beta$-scission may follow. Products of $\alpha$-scission include those that require primary carbocation intermediates if to be formed via $\beta$-scission. ${ }^{32}$

Technology selection for FTS product upgrading via cracking is based on the following considerations: FTS hydrocarbons are in principle hydrogen rich. Therefore, a carbon rejection strategy such as that in FCC is not essential, although applicable. ${ }^{33,34}$ In addition, the absence of contaminants like sulfur in FTS wax allows cracking under mild conditions and high partial pressures of hydrogen are not necessary (see below), thus hydrogen addition to the process would not become costly. On these grounds, hydrocrackers are the standard units for conversion of LTFT heavy

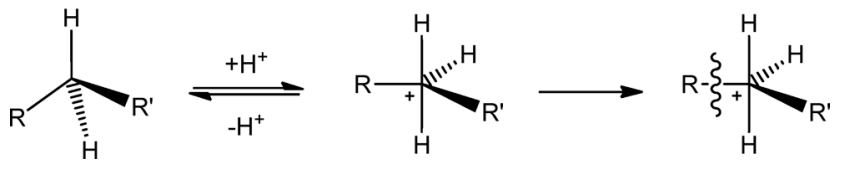

Fig. 4 Catalytic cracking by protonation of an alkane to form a pentacoordinated carbocation followed by $\alpha$-scission (protolysis). Adapted from ref. 2.<smiles>[R]CCC=CCC(C)CC[R]</smiles>

Fig. 3 Dimerization of a carbenium ion and an alkene. 
hydrocarbons to liquid fuels. ${ }^{1}$ Both process and catalysts involved are designed as such to be selective to the target hydrocarbon range (conventionally to middle distillates) and minimize over-cracking of the desired products. Further, they are optimized for production of branched hydrocarbons to improve the cold flow properties in case of diesel or octane number for gasoline-range hydrocarbons. ${ }^{35}$

As compared with the refinery hydrocrackers, these units are operated at much milder conditions in terms of temperature, pressure, and $\mathrm{H}_{2}$ /feed ratio in the case of FTS wax hydrocracking. This is due to the high reactivity of heavy paraffinic molecules in hydrocracking, plus the absence of strong catalyst poisons, such as sulfur and nitrogen containing compounds, in FTS wax. The involved catalysts are typically less acidic as well. ${ }^{36}$

A bifunctional FTS catalyst should be capable of catalyzing hydrocracking along with FTS at the process conditions of the latter. Although this is limited to speculation in many related reports, there are crystal clear indications that H-ZSM-5 satisfies this objective for the cracking functionality. ${ }^{37-44}$

In model reactions, Martínez et $a l^{38}$ showed that $n$-hexadecane conversion drops rapidly from $80 \%$ to zero over $\mathrm{H}-\mathrm{ZSM}-5(\mathrm{Si} / \mathrm{Al}=15)$ in $1 \mathrm{~h}$, regardless of co-feeding $\mathrm{H}_{2}$. However, a stable conversion level of $80 \%$ was measured once the same H-ZSM-5 was physically mixed with equal mass of $\mathrm{Co} / \mathrm{SiO}_{2}$. Since hardly any $\mathrm{C} 1$ was found in the reaction products, this stability improvement was attributed to the (de)hydrogenation activity of Co. In fact, reduced (non-sulfided) Co-containing catalysts have been explored for FTS wax hydrocracking elsewhere. ${ }^{45}$

A challenge that the hydrocracking component has to deal with under FTS reaction conditions is the presence of CO and $\mathrm{H}_{2} \mathrm{O}$. While the former may disturb the (de)hydrogenation functionality, $\mathrm{H}_{2} \mathrm{O}$ affects the acid-catalyzed reactions. Although stable, $n$-C16 conversion over H-ZSM-5 halved upon $\mathrm{H}_{2} \mathrm{O}$ addition to the feed stream. ${ }^{38}$ The negative effect of $\mathrm{CO}$ and $\mathrm{H}_{2} \mathrm{O}$ addition on $n$-dodecane hydroconversion was demonstrated over Ni/H-ZSM-5 $(\mathrm{Si} / \mathrm{Al}=66)$ extrudates (including $\mathrm{Al}_{2} \mathrm{O}_{3}$ as binder). ${ }^{41}$ The choice of $\mathrm{Ni}$ as the (de)hydrogenation function was on the basis that it is less sensitive than Pt to the presence of $\mathrm{CO}$. An almost $80 \% n$-C12 conversion drops to $c a .5 \%$ at $493 \mathrm{~K}$ after $\mathrm{CO}$ and $\mathrm{H}_{2} \mathrm{O}$ are co-fed in order to simulate an FTS environment. However, the conversion level can be increased to $\mathrm{ca}$. $80 \%$ by raising the reaction temperature to $533 \mathrm{~K}$. This $n$-C12 conversion was reasonably stable up to $70 \mathrm{~h}$ on-stream.

Since unsaturated hydrocarbons (mainly $\alpha$-olefins) are FTS primary products, they can be protonated directly by the acid catalyst even in absence of a (de)hydrogenation function. This is confirmed by results obtained in bifunctional reaction systems consisting of a catalyst bed of acid zeolite downstream that of an FTS catalyst bed (see section 4.1). Sartipi et $a .^{47}$ observed $\mathrm{C} 7-\mathrm{C} 9$ hydrocarbon formation along with C3-C5 during C6 hydroconversion over a mesoporous H-ZSM-5 catalyst at FTS process conditions. This observation points at the importance of the bimolecular mechanism during bifunctional FTS, as also suggested by others. ${ }^{9}$ C6 conversion considerably increases from 4 to $96 \%$ over mesoporous $\mathrm{H}-\mathrm{ZSM}-5(\mathrm{Si} / \mathrm{Al} \approx 40)$ by switching the reactant from $n$-hexane to 1-hexene (Fig. 6). ${ }^{46}$ Addition of a hydrogenation metal to the acid component in this case enhances the formations of isoparaffins. ${ }^{40,48,49}$

It is noteworthy that no $\mathrm{C} 1$ was observed in the product spectrum of mono-functional H-ZSM-5 catalysts. This result excludes the protolysis mechanism ( $\alpha$-scission) and rules out the acid-catalyzed reactions as origin of methane production during bifunctional FTS. A Co-containing catalyst may produce significant amounts of $\mathrm{C} 1$ through hydrocarbon hydrogenolysis (see Fig. 6 and section 3.2) while the selectivity to this product is low over Pt-containing hydrocracking catalysts (see Fig. 5).

Among zeolites H-ZSM-5 ( $\mathrm{Si} / \mathrm{Al} \approx 16)$, H-Beta $(\mathrm{Si} / \mathrm{Al} \approx 13)$, and $\mathrm{H}-\mathrm{Y}(\mathrm{Si} / \mathrm{Al} \approx 3)$, the first one shows the highest activity in $n$-C6 cracking followed by $\mathrm{H}$-Beta and $\mathrm{H}$-Y. The latter displayed the highest selectivity to $\mathrm{C} 6$ isomers. ${ }^{37} \mathrm{~A}$ more recent study ${ }^{43}$ demonstrates that only strong acid sites, active for hydrocracking at the operating temperature window of cobalt-based FTS catalysts, give rise to deviations from a conventional ASF product distribution (see also section 4.2).

\subsection{Other acid-catalyzed reactions of importance under FTS conditions}

Besides hydrocracking, an acidic zeolite may catalyze other reactions, including (but not limited to) hydroisomerization, oligomerization, aromatization, alcohol dehydration, etc. As explained in section 2.1, hydroisomerization and oligomerization intermediates are already involved in the hydrocracking mechanism. Thus, products of both reactions are expected during bifunctional FTS. Hydrocarbons up to C13 are formed through oligomerization reactions from a mixture of ethene and propene over $\mathrm{Pt} / \mathrm{H}-\mathrm{ZSM}-5$ and $\mathrm{Pt} / \mathrm{H}-\mathrm{Beta}$, regardless of

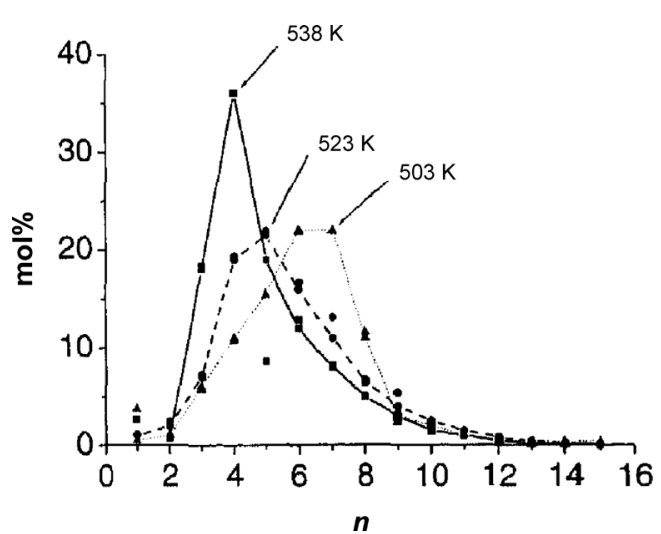

Fig. 5 Product distribution of $n$-hexadecane hydrocracking over $\mathrm{Pt}$ containing $\mathrm{H}-\mathrm{ZSM}-5(\mathrm{Si} / \mathrm{Al} \approx 16)$ extrudates (including $\mathrm{Al}_{2} \mathrm{O}_{3}$ as binder) at different temperatures. In addition to $n-C 16\left(S V_{n-C 16}=0.08-0.1 \mathrm{~h}^{-1}\right)$, the feed included $\mathrm{H}_{2} \mathrm{O}\left(\mathrm{SV}_{\mathrm{H} 2 \mathrm{O}}=0.25-0.3 \mathrm{~h}^{-1}\right)$ and syngas with the composition $\mathrm{N}_{2}: \mathrm{H}_{2}: \mathrm{CO}=50: 33: 16\left(\mathrm{GHSV}_{\text {gas }}=3600-3800 \mathrm{ll}_{\text {cat }}{ }^{-1} \mathrm{~h}^{-1}\right)$. $n$-C16 conversion is $33 \%, 83 \%$, and $100 \%$ at $503 \mathrm{~K}, 523 \mathrm{~K}$, and $538 \mathrm{~K}$, respectively. ${ }^{37}$ Reproduced with permission from Elsevier. 


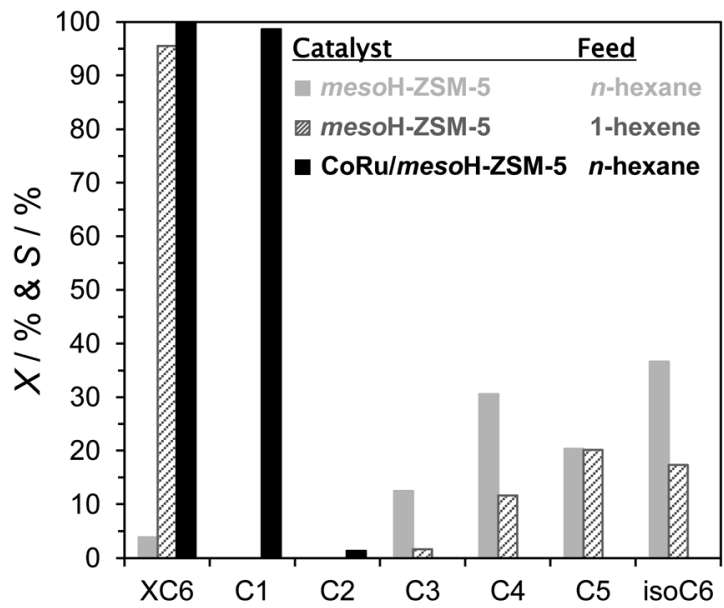

Fig. 6 Conversion and product selectivities in $\mathrm{C} 6$ hydroconversion over a mesoporous H-ZSM-5 (mesoH-ZSM-5) and 20 wt\% Co- 0.3 wt\% $\mathrm{Ru} / \mathrm{mesoH}-\mathrm{ZSM}-5$. Data were collected after $20 \mathrm{~h}$ on-stream at $513 \mathrm{~K}$, 15 bar total pressure, $\mathrm{H}_{2} / \mathrm{C} 6=9.0, \mathrm{~N}_{2} / \mathrm{H}_{2}=2.0$, and $S V=13 \mathrm{~mol}_{\mathrm{C} 6}$ $\mathrm{kg}_{\mathrm{cat}}{ }^{-1} \mathrm{~h}^{-1}$. Either $n$-hexane or 1-hexene was used, as indicated in the legend. ${ }^{46}$ Note that hydrocarbons larger than C 6 were also formed over mesoH-ZSM- 5 which were not specified. Reproduced with permission from Wiley-VCH Verlag GmbH \& Co.

syngas addition. The major products are mono-branched hydrocarbons in $\mathrm{C5}-\mathrm{C} 9$ range while $\mathrm{Pt} / \mathrm{H}-\mathrm{ZSM}-5$ is more active than $\mathrm{Pt} / \mathrm{H}$-Beta. ${ }^{40}$ The significant oligomerization activity of H-ZSM-5 reduces the production of lower olefins when this zeolite is added to the FTS catalyst, whereas this effect is less for H-Beta and $\mathrm{H}_{-M O R}{ }^{50}$ and is not observed for mixtures containing MCM-22, ITQ-2, and ITQ-22. ${ }^{51}$ The C2-C4 range olefin to paraffin ratio decreases with a decrease in $\mathrm{Si} / \mathrm{Al}$ ratio of $\mathrm{H}-\mathrm{ZSM}-5$, when physically mixed with a Fe-based FTS catalyst, ${ }^{52}$ which further highlights the occurrence of olefin oligomerization over this zeolite in bifunctional FTS.

In principle, zeolites having more acid sites of medium strength show higher isomerization activity, whereas stronger acid sites catalyze cracking. ${ }^{2}$ In line with this general statement, mesoporous H-ZSM-5 ( $\mathrm{Si} / \mathrm{Al} \approx 40)$ was compared with H-ITQ-2 $(\mathrm{Si} / \mathrm{Al} \approx 40)$ and mesoporous $\mathrm{H}$-USY $(\mathrm{Si} / \mathrm{Al} \approx 40)$ for the effect of their acid strength and density on catalytic performance. ${ }^{43}$ While the former shows activity in $n$-C6 hydrocracking, H-ITQ-2, having even a higher density of weaker acid sites, catalyzes only the isomerization reaction and mesoporous H-USY was inactive under the applied process conditions. Both mesoporous H-ZSM-5 and H-ITQ-2 supported Co-catalysts yield a similar ratio of iso- to $n$-C4 in FTS, but the former is considerably more selective to the $\mathrm{C5}-\mathrm{C} 11$ fraction due to cracking of large FTS hydrocarbons, resulting in a non-ASF product distribution (Fig. 7). Further comparing the product slate of Co supported on the three above-mentioned zeolites, revealed that hydrocarbon isomerization alone is not enough to lead to non-ASF catalytic behavior. ${ }^{43}$ It was concluded that an outstanding isomerization activity might only decrease the chain growth probability (Fig. 7), since branched hydrocarbons may not participate in chain propagation as effectively as linear ones.

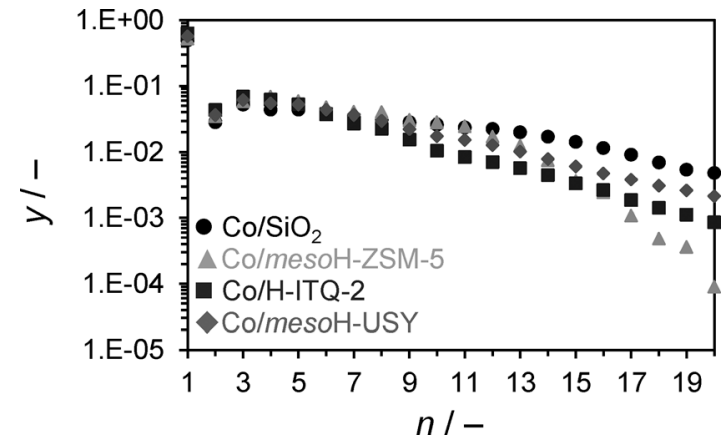

Fig. 7 Molar fractional distribution of FTS products after $140 \mathrm{~h}$ onstream at $513 \mathrm{~K}, 15$ bar total pressure, feed composition $\mathrm{H}_{2} / \mathrm{CO}=1$, and GHSV $=12 \mathrm{~m}_{\mathrm{STP}}{ }^{3} \mathrm{~kg}_{\mathrm{cat}}{ }^{-1} \mathrm{~h}^{-1}$. Co/mesoH-ZSM-5: mesoporous $\mathrm{H}$-ZSM-5-supported $\mathrm{Co}$; $\mathrm{Co} /$ mesoH-USY: mesoporous H-USY-supported Co. Co loadings are about $20 \mathrm{wt} \% .{ }^{43}$ Reproduced with permission from Wiley-VCH Verlag GmbH \& Co.

At low temperatures, hydrocracking catalysts effectively catalyze the hydroisomerization reaction. The extent of hydrocracking relative to hydroisomerization can be tuned by adapting the process conditions, acid strength, and the ratio between metal and acid sites in a catalyst. At temperatures below $523 \mathrm{~K}$, hydroisomerization of 1-octene over Pt/H-ZSM-5 $(\mathrm{Si} / \mathrm{Al}=32)$ dominates over hydrocracking in the presence of CO. The contrary holds at higher temperatures and/or in absence of $\mathrm{CO}^{40}$ Process temperatures of LTFT favor hydroisomerization and oligomerization rather than hydrocracking over H-ZSM-5 catalysts. Oligomerization of lower olefins followed by the limited growth of branched hydrocarbons (that are produced by hydroisomerization, oligomerization, and hydrocracking) effectively stops the chain propagation at around $\mathrm{C} 10$ while the large hydrocarbons are very reactive to hydrocracking. ${ }^{53}$ This may explain why most of the reported bifunctional catalysts, operated at LTFT conditions, are selective towards gasoline-range hydrocarbons rather than the diesel range (which is the desired product of the conventional two-steps LTFT and hydrocracking process).

On the other hand, HTFT conditions are typically associated with low chain growth probabilities and target gasolinerange hydrocarbons, lower olefins, and oxygenates. Consistent results show that FTS oxygenates are dehydrated by zeolites in bifunctional systems. ${ }^{54-56}$ As long as liquid fuels are targeted, HTFT is followed by isomerization and reforming units to improve the octane number of the produced gasoline. Bifunctional catalysts that contain zeolites are reported to produce notable amounts of aromatic compounds ${ }^{51,57-59}$ and olefins, which essentially can improve the octane number. However, a high production of aromatics may result in severe deactivation of the acid catalyst (see section 5). Formation of aromatics may become smaller at lower operating temperatures. $^{46}$

\section{Side reactions at the metal sites}

The main function of metal sites with respect to the present application is FTS, i.e., chain propagation (e.g., via CO 
insertion) and hydrogenation. In the current context, FTS performance in combination with acid functionality is included in section 4, while two important side reactions are described in this part.

\subsection{Hydrogenation}

$\mathrm{Co}^{\circ}$ is the FTS active phase in Co-based catalysts whereas carbides form over $\mathrm{Fe}^{0}$ in an early stage of the FTS reaction or during the catalyst activation by means of CO. These carbon containing species are believed to effectively catalyze FTS rather than metallic Fe. ${ }^{60}$ In parallel, hydrogenation is anticipated over both Co- and Fe-based catalysts. In addition to saturation of olefinic hydrocarbons, this reaction directly converts CO into methane. Fig. 8 shows that, as compared with a Fe-catalyst and in spite of a lower reaction temperature, the methane level is higher than what is anticipated by extrapolating the ASF distribution to $n=1$ over a Co-catalyst. This is due to the higher hydrogenation activity of Co in comparison with $\mathrm{Fe}$, which makes this side reaction more important over the former. Therefore, Co FTS catalysts are known to be more sensitive than Fe-based catalysts to changes in $\mathrm{H}_{2}$ concentration and/or process temperature. ${ }^{61,62}$

De Jong et al. ${ }^{63}$ showed that methane selectivity through CO hydrogenation sharply increases as Co particle size becomes smaller than 6-10 $\mathrm{nm}$, while for larger sizes the reaction is not structure sensitive. The density of lower index surface crystallographic planes or steps and corners increases as particle size decreases. ${ }^{64}$ The higher methane selectivity of small particles is mainly brought about by their higher hydrogen coverage ${ }^{65}$ and the high activity of low coordination sites, residing at corners and edges. ${ }^{66}$

As compared with conventional catalysts, more heterogeneous Co sites are found when supported on a zeolite via impregnation. ${ }^{44,46}$ For example, infrared (IR) spectra of preadsorbed CO (Fig. 9) show that low frequency bands at 1988-2020 $\mathrm{cm}^{-1}$ are clearly detected over an H-ZSM-5-supported

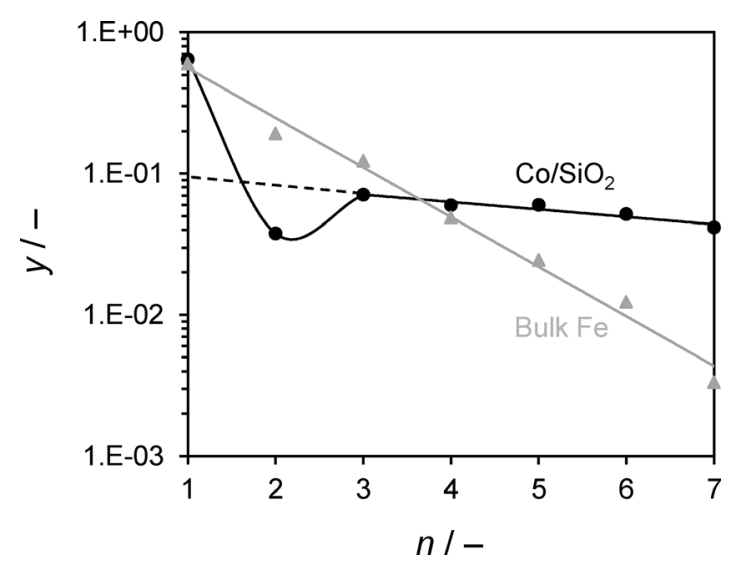

Fig. 8 Molar fractional distribution of FTS products over $20 \mathrm{wt} \% \mathrm{Co} /$ $\mathrm{SiO}_{2}$ and a bulk Fe-catalyst after $5 \mathrm{~h}$ on-stream. Experiments were performed at 15 bar total pressure, feed composition $\mathrm{H}_{2} / \mathrm{CO}=1513 \mathrm{~K}$ and $523 \mathrm{~K}$ for $\mathrm{Co} / \mathrm{SiO}_{2}$ and bulk Fe, respectively, GHSV/m $\mathrm{STP}^{3} \mathrm{~kg}_{\mathrm{cat}}{ }^{-1} \mathrm{~h}$ ${ }^{-1}=12$ and 24 for $\mathrm{Co} / \mathrm{SiO}_{2}$ and bulk $\mathrm{Fe}$, respectively.
Co while these bands are less pronounced over $\mathrm{Co} / \mathrm{SiO}_{2}$. Such IR bands are assigned to linearly adsorbed $\mathrm{CO}$ on $\mathrm{Co}^{0}$ centers of lower coordination that are more located on open lowindex surface crystallographic planes or steps and corners. ${ }^{67-69}$ Therefore, direct $\mathrm{CO}$ hydrogenation $\left(\mathrm{CO}+3 \mathrm{H}_{2} \rightarrow \mathrm{CH}_{4}+\mathrm{H}_{2} \mathrm{O}\right)$ partly explains the relatively high methane production over zeolite-supported Co-catalysts (even in the absence of Brønsted acidity) and can be rationalized on the basis of the strong metal-support interaction on the structured aluminosilicate. ${ }^{44,46}$

Due to their lower intrinsic activity, relatively high reaction temperatures are employed for Fe-base catalysts even in LTFT applications. Higher reaction temperatures will lead to a decrease in FTS chain growth probability and thus higher production of methane through FTS. In spite of this, the C1 selectivity is almost similar over both $\mathrm{SiO}_{2}$ and zeolitesupported Fe-catalysts. ${ }^{70}$ In some occasions, it is claimed that H-ZSM-5 would even enhance the formation of the active carbide phase and improve the catalyst performance. ${ }^{71}$

\subsection{Hydrogenolysis}

Other than hydrogenation, a hydrocarbon may undergo many types of reactions over metals, namely hydrogenolysis,

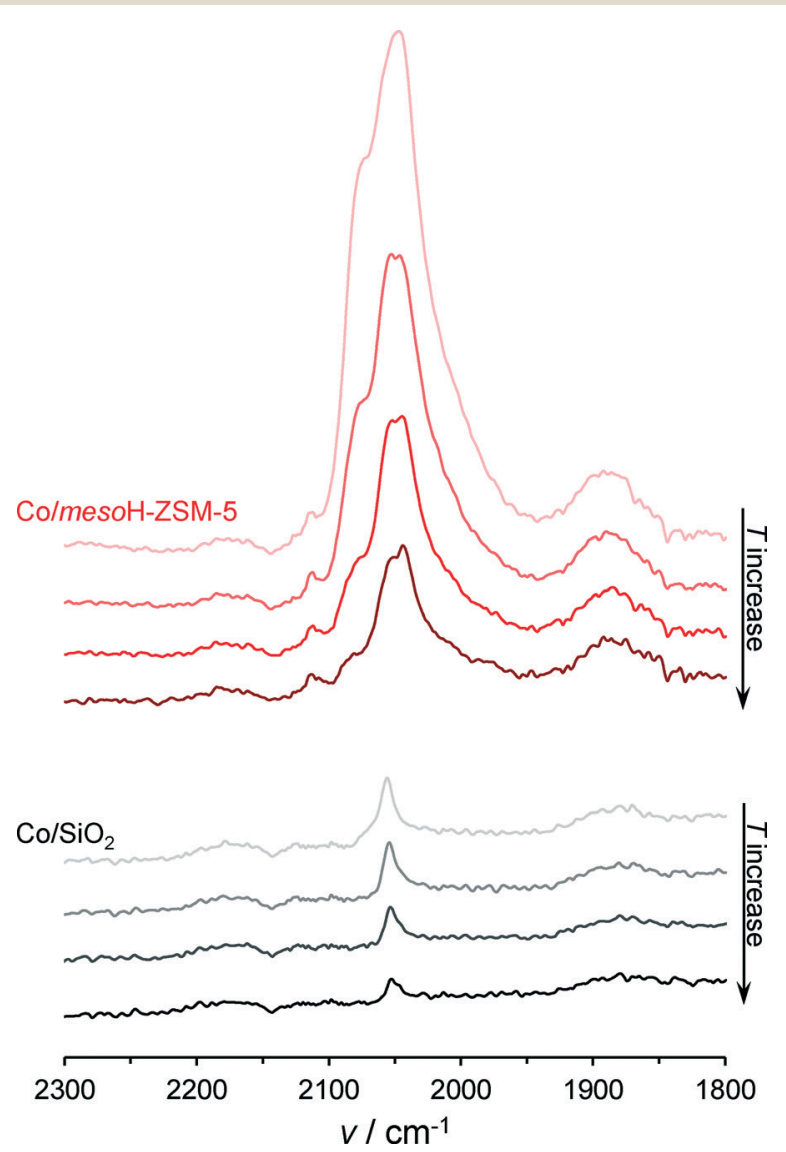

Fig. 9 IR spectra of pre-adsorbed $\mathrm{CO}$ on $\mathrm{Co} / \mathrm{SiO}_{2}$ (bottom data set) and mesoporous $\mathrm{H}$-ZSM-5-supported $\mathrm{Co}\left(\mathrm{Co} / \mathrm{mesoH}^{\mathrm{Z}} \mathrm{ZSM}-5\right.$, top data set). In each data set, the temperature is increased in a DRIFTS cell to $373,423,473$, and $513 \mathrm{~K}$, respectively, according to the arrows. Co loadings are about $10 \mathrm{wt} \%$. 
isomerization, dehydrocyclization, and aromatization. ${ }^{72}$ Except for hydrogenolysis, most of these reactions do not occur in the FTS reaction environment as evidenced by negligible presence of branched, cyclic, and aromatic hydrocarbons in conventional FTS products. It should be noted that in bifunctional catalysts, some of the above-mentioned reactions become important over acid sites, as already discussed in section 2 .

Hydrogenolysis is an exothermal reaction, catalyzed by group VIII metals (including $\mathrm{Ru}, \mathrm{Co}, \mathrm{Fe}$, and $\mathrm{Ni}$ ). This reaction proceeds via formation of adsorbed hydrocarbon radicals as reaction intermediates followed by $\mathrm{C}-\mathrm{C}$ scission. In contrast to hydrocracking, the adsorbed radical intermediate mechanism results in low isomerization activity and therefore unbranched products. ${ }^{45}$

Different mechanisms have been proposed for hydrogenolysis of saturated hydrocarbons. In all cases the reaction is initiated by dehydrogenative chemisorption of the hydrocarbon. ${ }^{73,74}$ As first example, ethane hydrogenolysis proceeds via 1,2-adsorbed intermediates followed by a series of elementary steps that lead to formation of hydrogen deficient surface species. $^{75}$

$$
\begin{aligned}
& \mathrm{C}_{2} \mathrm{H}_{6} \rightleftarrows \mathrm{C}_{2} \mathrm{H}_{5}(\text { ads })+\mathrm{H}(\text { ads }) \\
& \rightleftarrows \mathrm{C}_{2} \mathrm{H}_{x}(\text { ads })+a \mathrm{H}_{2}(a=(6-x) / 2) \\
& \mathrm{C}_{2} \mathrm{H}_{x}(\text { ads })+\mathrm{H}_{2} \rightarrow \text { adsorbed } \mathrm{C} \text { fragments } \stackrel{\mathrm{H}_{2}}{\longrightarrow} \mathrm{CH}_{4}
\end{aligned}
$$

C-C scission results from the reaction between the adsorbed intermediate and $\mathrm{H}_{2}$, being the rate determining step. ${ }^{73}$ As the ratio of dehydrogenation-to-hydrogenolysis activity of a metal increases, lower $x$ values (reaction (1)) are expected. Thus, values of 4 and 2 are reported for Co and $\mathrm{Ni}$, respectively. ${ }^{76}$ It is noteworthy that $\mathrm{H}_{2}$ pressure has a strong inverse effect on the reaction rates over most group VIII metals except for $\mathrm{Fe}$ and $\mathrm{Re}$. This has been explained by a decrease in the concentration of $\mathrm{C}_{2} \mathrm{H}_{x}(\operatorname{ads})$ with increasing $\mathrm{H}_{2}$ pressure. ${ }^{73}$ The specific activity of group VIII metals for ethane hydrogenolysis follows the following order: ${ }^{77} \mathrm{Os}>\mathrm{Ru}$ $>\mathrm{Ni}>\mathrm{Rh}>\mathrm{Ir}>\mathrm{Re}>\mathrm{Co}>\mathrm{Fe}>\mathrm{Cu}>\mathrm{Pt} \approx \mathrm{Pd}$, while for propane Co shows a higher activity than $\mathrm{Ni}^{78}$

The rate of hydrogenolysis increases with the carbon number of alkanes which is attributed to lower average dissociation energies of $\mathrm{C}-\mathrm{C}$ bonds in larger molecules. ${ }^{79}$ As an example, $n$-heptane hydrogenolysis is several orders of magnitude faster than that of ethane at $478 \mathrm{~K}^{76}$

Alternatively, Anderson and Avery proposed 1,3-adsorbed intermediates for isomerization and hydrogenolysis of simple aliphatic hydrocarbons larger than C2. In this scheme, one carbon atom is doubly bonded to a surface metal atom (Fig. 10). ${ }^{80}$ If the C-metal double bond is located primarily at the terminal $\mathrm{C}$ atom, and assuming that the $\mathrm{C}-\mathrm{C}$ bond adjacent to the $\mathrm{C}$-metal double bond cracks preferentially, then methane will be the main product of hydrogenolysis.

The distribution of primary hydrogenolysis products depends on the metal. On $\mathrm{Ni}$, the reaction scheme involves successive demethylation at terminal $\mathrm{C}-\mathrm{C}$ bonds of the

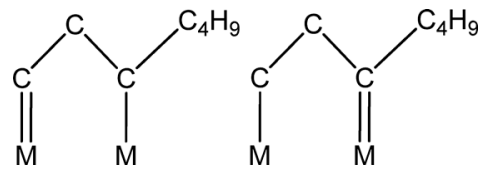

Fig. 10 Structure of adsorbed $n$-heptane intermediates formed on metals. ${ }^{79}$

hydrocarbon chain which lead to formation of C1 fragments that are hydrogenated to form methane. ${ }^{45,81}$ This scheme also applies reasonably well to Co, but not to $\mathrm{Fe}^{81}$ This explains the significant amounts of $\mathrm{C} 1$ and $\mathrm{C} 2$, reported over hydrocracking catalysts that contain Ni or Co as the (de)hydrogenation function. ${ }^{35}$

In contrast, a nonselective rupture of different $\mathrm{C}-\mathrm{C}$ bonds is reported over Pt-containing catalysts. For $n$-heptane, hydrogenolysis was the predominant reaction on all the metals of group VIII except Pt, on which extensive isomerization and dehydrocyclization were also observed. ${ }^{82}$ The lower hydrogenolysis activity of noble metals, as compared with very active hydrogenation metals such as $\mathrm{Ni}$, makes them the preferred choice for (de)hydrogenation functionality when employed in hydrocracking and hydroisomerization catalysts.

Some reports speculate that hydrogenolysis may add to methane production over bifunctional FTS catalysts. ${ }^{9,44,77}$ Related literature on this aspect is not clear and even controversial in some occasions. $n$-hexadecane hardy showed any conversion over $\mathrm{Co} / \mathrm{SiO}_{2}$ at $523 \mathrm{~K}\left(\mathrm{H}_{2} / n-\mathrm{C} 16=2.9, \mathrm{~N}_{2} / n-\mathrm{C} 16=4.4\right) .{ }^{38}$ In another study however, ca. 25\% $n$-hexane conversion is reported over $\mathrm{Co} / \mathrm{SiO}_{2}$ at $493 \mathrm{~K}$ where $\mathrm{C} 1$ was dominantly produced $\left(\mathrm{H}_{2} / n\right.$-C6 $=9.0, \mathrm{~N}_{2} / n$-C6 $\left.=2.0\right) .{ }^{44}$ Under similar conditions, Co/H-ZSM-5 was more than $50 \%$ selective towards methane while no C1 was detected over H-ZSM-5. The n-C6 conversion over Co/H-ZSM-5 and H-ZSM-5 was 94 and $13 \%$, respectively. ${ }^{44}$ Accordingly, zeolite-supported Cocatalysts that contain a large fraction of coordinatively unsaturated Co sites are more active than $\mathrm{Co} / \mathrm{SiO}_{2}$ in $n$-C6 hydrogenolysis. ${ }^{4,46}$ This reaction is known to be structure sensitive and TOFs often vary with particle size. Nevertheless, there is no consistency in literature on the type of such dependence. ${ }^{83}$ In any case due to competitive CO adsorption under FTS reaction conditions, hydrogenolysis is not expected to occur to such an extent as in the absence of CO. Including propane in a syngas feed did not significantly change the methane selectivity, and ethylene and propylene addition even reduced this value, ${ }^{77}$ probably due to reinsertion and scavenging of $\mathrm{C} 1$ surface species. Further investigations, e.g., via labeling the reactant molecules, are required in order to (completely) unveil the extent of hydrocarbon hydrogenolysis as side reaction during FTS.

\section{Zeolite-containing FTS systems}

From the perspective of Catalysis Engineering, ${ }^{84}$ three different process levels can be distinguished in bifunctional FTS catalysts based on the state and extent of the contact between the acidic and FTS function: the reactor level, the catalyst 
particle level and the catalyst active phase level. These three levels are thoroughly discussed in this section.

\subsection{Reactor level}

Two different configurations can be distinguished in literature for combination of zeolites and FTS metals (Co and Fe) at the reactor level: separate or dual layer beds, containing the zeolite downstream of the FTS catalyst (denoted as '2BED'), and single mixed beds containing a homogeneous physical mixture of the two catalysts (denoted as '1BED') (Fig. 11). Both catalyst beds can be operated at a similar temperature, which is in the limit of either LTFT or HTFT conditions. Applications with a higher temperature at the zeolite bed region, closer to that of hydrocrackers, or even dual reactor systems have also been reported. ${ }^{85,86}$ Such layouts resemble the two step processes (such as in the Shell SMDS ${ }^{1}$ ) and are not discussed in this context. 1BED systems may be considered as at the border between the reactor and catalyst particle levels and their related discussions are divided between sections 4.1 and 4.2 .
Both Fe- and Co-based FTS have been studied in the two above-mentioned configurations (2BED and 1BED). Severe alkali migration from the alkali-promoted Fe-containing catalysts to H-ZSM-5 is reported for 1BED during the course of reaction. ${ }^{57,59}$ As a result, a decline in FTS activity ${ }^{59}$ and a considerable selectivity shift towards lower value light paraffins (including $\mathrm{C} 1)^{57}$ make the $1 \mathrm{BED}$ configuration less attractive than the 2BED. In contrast, higher $\mathrm{CO}$ conversions and C5-C11 selectivity were obtained in 1BED when a La-promoted Fe was studied. ${ }^{55}$

The improved performance of 1BED over 2BED systems in terms of increased selectivities to gasoline-range hydrocarbons is in line with results reported for Co-based catalysts. ${ }^{40,41,54}$ Schaub et al. ${ }^{40,41}$ reveal that under the applied process conditions, the $\mathrm{C} 10-\mathrm{C} 20$ molar fraction may be larger in the 2BED configuration than in the 1BED, while both systems represent similar fractions of liquid hydrocarbons $(\mathrm{C} 5-\mathrm{C} 20){ }^{40}$ In any case, the 1BED operation leads to more branched hydrocarbons, ${ }^{40,41,54}$ pointing to an enhanced contribution of acid-catalyzed reactions in the latter.

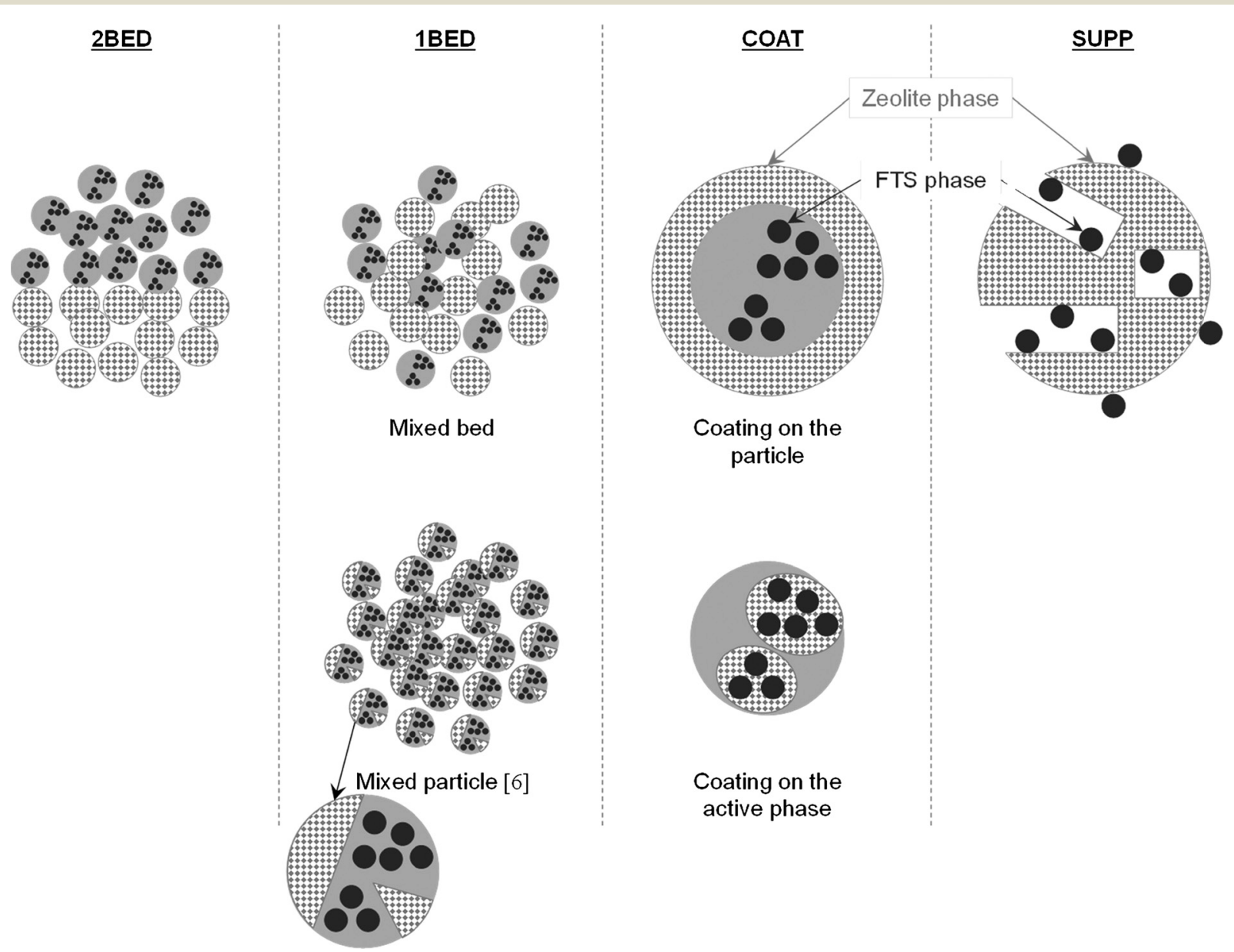

Fig. 11 Schematic representation of different configurations that zeolite and FTS phases may have with respect to one another in bifunctional systems. From left to right: separate or dual layer beds, containing the zeolite downstream the FTS catalyst (2BED), single mixed bed containing a homogeneous physical mixture of the zeolite and FTS catalyst particles (1BED), coating layer of the zeolite over FTS catalyst (COAT), and FTS active phase supported on the zeolite (SUPP). 
Many reports indicate that the $\mathrm{C} 1$ selectivity increases as the bed configuration changes from $2 \mathrm{BED}$ to $1 \mathrm{BED}^{9,40,41,55,77}$ and various reasons, including acid cracking, hydrocarbon hydrogenolysis, heat effects, etc. are hypothesized as possible origins. FTS is highly exothermic and heat effects are typically eliminated by diluting the catalyst bed with an inert and/or recycle of liquid product. However, some acid zeolite catalyzed reactions, including hydrocracking, as well as possible hydrocarbon hydrogenolysis over metal sites are also exothermic and may add to the produced heat. The C1 selectivity was reduced by half upon adding an inert solid to a physical mixture of $\mathrm{Co} / \mathrm{SiO}_{2}$ and $\mathrm{H}-\mathrm{ZSM}-5$ while it did not change in the absence of the zeolite. Furthermore, less aromatics were detected in the liquid products after dilution. ${ }^{77}$ These results indicate that heat effects are even more important in bifunctional systems, especially in 1BED configuration. In more recent studies, zeolites H-USY, H-Beta, H-MOR, and H-ZSM-5 that were mixed with $\mathrm{Co} / \mathrm{SiO}_{2}$ and diluted with $\mathrm{SiC}$ in a 1BED configuration, did not lead to additional $\mathrm{C} 1$ at all. ${ }^{38,87}$ This observation suggests that reactions over the acid zeolites do not produce additional methane.

\subsection{Catalyst particle and active phase levels}

1BED systems may also consist of catalyst particles that are homogeneous mixtures of zeolite and FTS phases (Fig. 11). A closer contact (than that in the 1BED configuration) between the FTS and zeolite functionalities is possible if a coating layer of the latter is put over the FTS active phase ${ }^{88-90}$ (denoted as 'COAT'). As schematically shown in Fig. 11, the zeolite layer may coat the catalyst particle (i.e., coating of $\mu \mathrm{m}$ sized particles) or the FTS metal agglomerates (i.e., coating of nm sized particles). The contact can be further maximized by dispersing the FTS metal particles in a zeolitic support ${ }^{42,47,89,91}$ (denoted as 'SUPP').

For Fe-based catalysts it is shown that SUPP $^{92}$ and $\mathrm{COAT}^{71,93}$ systems are more selective than 1BED to the C5-C11 fraction. Accordingly, an intimate contact between the two components is a key to the bifunctional performance of these hybrid catalysts. A systematic study on Co-catalysts revealed that upon changing the system configuration from 1BED to COAT and further to SUPP (Fig. 11), deviations form a classical ASF product distribution become more pronounced (Fig. 12). ${ }^{89}$ This practical observation is an evidence of the above statement about the necessity of the close proximity of the two types of active sites.

The COAT configuration concept may be termed 'coreshell' as described by Tsubaki et al. ${ }^{94,95}$ for FTS reaction in analogy to earlier studies for other reactions. ${ }^{96,97}$ In an ideal core-shell scenario, a defect free reactive zeolite membrane should cover a core of FTS catalyst. A critical review of the relatively large number of reports on this topic, ${ }^{49,71,88,90,93-95,98-110}$ points to the challenge of making and characterizing such catalytic membrane reactor on the level of catalyst particles (i.e., coating of $\mu \mathrm{m}$ sized particles) via the hydrothermal synthesis approach: ${ }^{89}$ exposing a $\mathrm{Co} / \mathrm{SiO}_{2}$ core to a hydrothermal

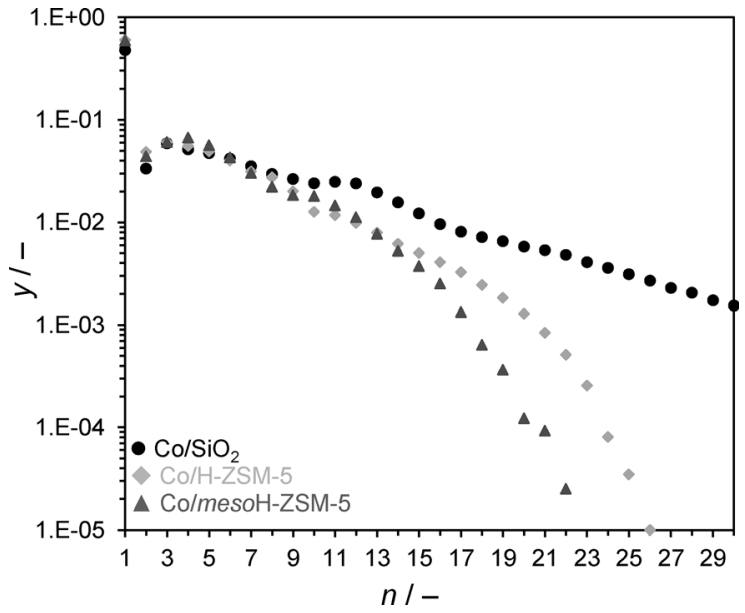

Fig. 12 Fractional molar distribution of FTS products after $20 \mathrm{~h}$ onstream at $513 \mathrm{~K}, 15$ bar total pressure, feed composition $\mathrm{H}_{2} / \mathrm{CO}=2$, and GHSV $=2.4 \mathrm{~m}_{\mathrm{STP}}{ }^{3} \mathrm{~kg}_{\mathrm{cat}}{ }^{-1} \mathrm{~h}^{-1}$. Co/mesoH-ZSM-5: mesoporous $\mathrm{H}$-ZSM-5-supported Co. Co loadings are about $10 \mathrm{wt} \%{ }^{89}$ Reproduced with permission from Elsevier.

environment in the presence of zeolite structure directing agent, brings about partial transformation of the $\mathrm{SiO}_{2}$ into zeolite where Co agglomerates are enwrapped (i.e., coating of nm sized particles). In other words, the supported Co-catalyst functions as a synthesis precursor during the hydrothermal approach rather than as an ideal catalyst core. ${ }^{88}$ Regardless of the necessity for in depth characterization, good selectivity data to gasoline-range hydrocarbons and/or isoparaffins are reported for both Fe- and Co-based COAT systems ${ }^{71,98,105}$ along with too high $\mathrm{C} 1$ selectivity. At the same time, Co-based coated catalysts exhibit lower $\mathrm{CO}$ conversion levels than the conventional base catalysts ${ }^{88,89,94,95,98-110}$ due to mass transport limitations. ${ }^{89}$ Unfortunately, the majority of the FTS reactions catalyzed by coated catalysts are reported at very high conversion levels of the limiting reactants (e.g., $>90 \% \mathrm{CO}$ conversion at $\mathrm{H}_{2} / \mathrm{CO}$ ratio of 2 (ref. 49, 90, 93)) which is not desired for activity evaluations. ${ }^{111}$ Since FTS catalysts in general are not highly productive, a loss in activity should be considered as a significant obstacle for practical applications. One report claims that an intimate contact with H-ZSM-5 promotes the formation of an active carbide phase in Fe-containing catalysts and hence, enhances the catalyst activity: $^{71}$ the authors report a $90 \%$ CO conversion for H-ZSM-5-coated Fe-catalyst after $c a .150 \mathrm{~h}$ on-stream which is ca. $30 \%$ higher than that over the uncoated sample. However, since this reaction was performed at $\mathrm{H}_{2} / \mathrm{CO}$ ratio of 1 (which is half of the stoichiometric value of 2), products associated with ca. $15 \%$ of the converted CO are not clearly stated (olefin/paraffin ratio of 0.9 and $17 \%$ carbon selectivity to $\mathrm{CO}_{2}$ are reported).

Alternatively, the cooperative action of FTS and acid sites can be enhanced by employing the acidic zeolite as FTS catalyst support (SUPP, Fig. 11). However, such an application is restricted by the limited external surface area of zeolites. Dispersion of metals in the zeolite micropores reduces their FTS 
activity and selectivity for the following reasons: (i) due to stronger metal-support interactions, metal reducibility decreases considerably inside the zeolite structure, ${ }^{46,112}$ (ii) even on inert carriers, it is well-known that Co particles smaller than 6-10 nm in size are not optimal for FTS (section 3.1), ${ }^{63,65}$ and (iii) mass transport limitations in the very narrow zeolite micropores may severely alter the local $\mathrm{H}_{2} / \mathrm{CO}$ ratio with respect to that in the bulk and also lead to overexposure of the hydrocarbon products to acid sites. ${ }^{42,47}$ To address these drawbacks mesopores were created in crystallites of different zeolites via desilication ${ }^{113}$ and the resulting hierarchical zeolites were employed as support for $\mathrm{Co}^{43,44,46,47,89}$ and $\mathrm{Ru} .{ }^{42,91}$ For 3 wt\% Ru-catalysts supported on ZSM-5 and Beta, product selectivity correlates with the extent of support mesoporosity: upon increasing the $\mathrm{NaOH}$ concentration (employed desilicating agent) and thus creating more mesoporosity, the selectivity to methane decreases (over the prospect catalyst) while that to gasoline-range hydrocarbons increases. ${ }^{42,91}$ This has been attributed to reduced diffusion limitations, which eliminate the overexposure of the FTS hydrocarbons to strong acid sites and keep the local $\mathrm{H}_{2} / \mathrm{CO}$ ratio inside the catalyst particle closer to bulk conditions. ${ }^{42,47}$ Nevertheless, very high concentrations of $\mathrm{NaOH}$ results in excessive zeolite amorphization and lowers the C5-C11 selectivity by reducing the acid-catalyzed reaction. Therefore, synthesis optimization of mesoporous zeolites should be realized specifically for FTS catalyst applications. In a series of reports by Sartipi et al., ${ }^{43,44,46,47,89}$ synthesis optimization of mesoporous H-ZSM-5 (denoted as ' $m e s o H-Z S M-5$ ') involved demetalation via subsequent base and acid treatments. $\mathrm{NaOH}$ (alkaline) and tetrapropylammonium hydroxide (TPAOH, organic) bases were employed as desilicating agents. Under similar treatment conditions, $\mathrm{NaOH}$ results in a more severe desilication than TPAOH, ${ }^{47}$ creating mesostructures with pore sizes and volumes very similar to the amorphous $\mathrm{SiO}_{2}$ reference support. ${ }^{44,47}$ A more controlled desilication with TPAOH gives rise to more mesoporosity suggesting a higher degree of hierarchy with large cavities communicated with smaller mesopores. ${ }^{46,47}$ Further, TPAOH is preferred over $\mathrm{NaOH}$, since $\mathrm{Na}^{+}$is a well-known poison for Co-based FTS catalysts and trace amounts results in a lower FTS activity as compared with the organic treated samples. ${ }^{47}$

The consecutive acid treatment (with $\mathrm{HNO}_{3}$ ) removes the produced extraframework aluminum, caused by zeolite desilication, and boosts the FTS activity. Moreover, the acid treatment increases the Brønsted acidity of mesoH-ZSM-5. ${ }^{44}$

The large mesopore surface area of mesoH-ZSM-5 improves the metal dispersion at elevated Co loadings. The $\mathrm{Co} /$ mesoH-ZSM-5 catalyst is much more active than $\mathrm{Co} / \mathrm{H}-\mathrm{ZSM}-5$ and the conventional $\mathrm{Co} / \mathrm{SiO}_{2} \cdot{ }^{44,89}$ Moreover, the time-onstream stability of $\mathrm{Co} /$ meso $\mathrm{H}-\mathrm{ZSM}-5$ and $\mathrm{Co} / \mathrm{SiO}_{2}$ is comparable, in terms of CO conversion, during $140 \mathrm{~h}^{43,46}$ (insert in Fig. 13a). The high selectivity to liquid hydrocarbons over $\mathrm{H}-$ ZSM-5-supported catalysts is visible as a cutoff in the molar distribution above $\mathrm{C11}$ in terms of the ASF distribution of conventional catalysts (e.g., $\mathrm{Co} / \mathrm{SiO}_{2}$, Fig. 7 and 12). Measurements after $140 \mathrm{~h}$ on-stream shows that Co/mesoH-ZSM-5 is ca. three times more selective than $\mathrm{Co} / \mathrm{SiO}_{2}$ towards $\mathrm{C} 5-\mathrm{C} 11$ cut, producing a large fraction of unsaturated hydrocarbons, other than $\alpha$-olefins. Moreover, wax production is considerably suppressed over the zeolite-containing catalyst ${ }^{46}$ (Fig. 13).

\section{Stability of zeolites in view of bifunctional FTS applications}

One of the major concerns regarding industrial applications of zeolite-containing bifunctional catalysts is the stability and lifetime of the acid component with respect to that of the FTS. In this view, coke formation is a main parameter, since deposition of coke would eventually deactivate the acid

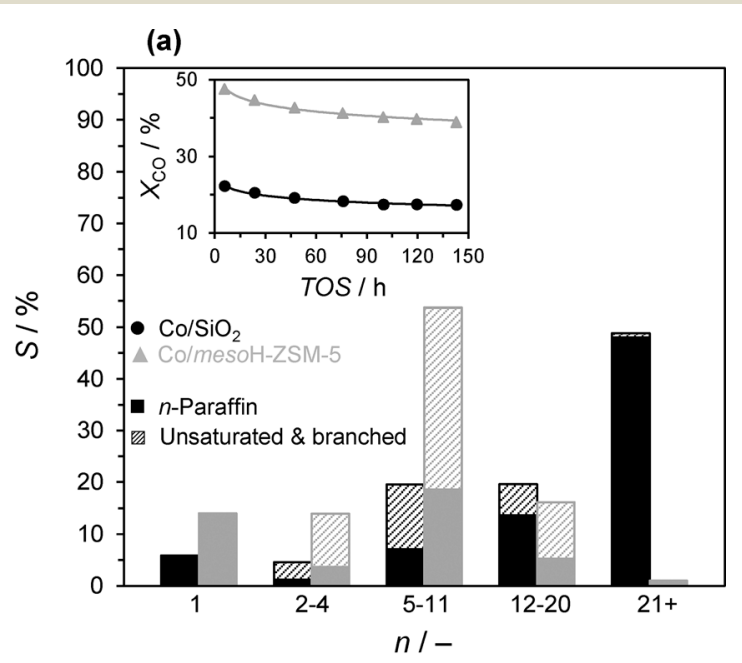

(b)

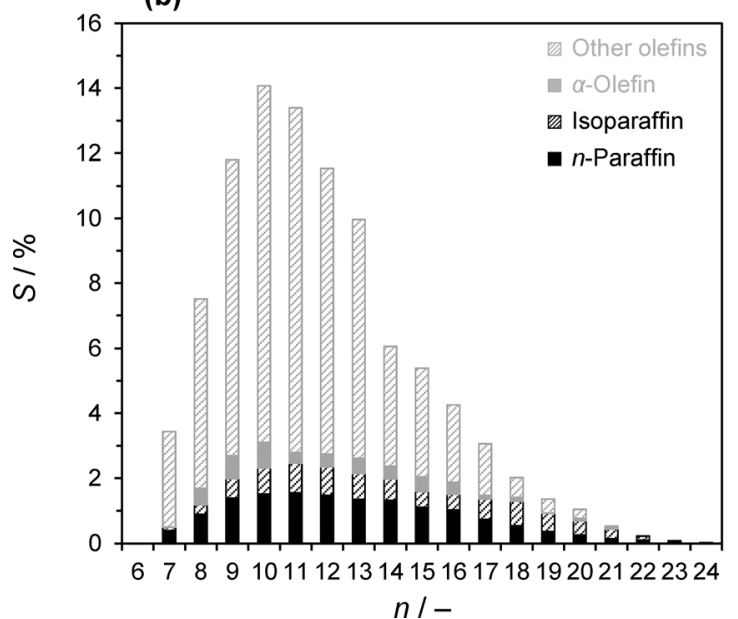

Fig. 13 (a) Carbon selectivity of FTS products after $140 \mathrm{~h}$ on-stream. In each carbon number group from left to right: $\mathrm{Co} / \mathrm{SiO}_{2}$ and $\mathrm{Co} /$ mesoH-ZSM-5. n: $n$-paraffins; : sum of isoparaffins and olefins. Insert shows the time-on-stream (TOS) evolution of the CO conversion. (b) Selectivity distribution of liquid hydrocarbons, produced over Co/ mesoH-ZSM-5 as collected after $140 \mathrm{~h}$ on-stream. FTS experiments were performed at $513 \mathrm{~K}, 15$ bar total pressure, feed composition $\mathrm{H}_{2} /$ $\mathrm{CO}=1$, and GHSV $=12 \mathrm{~m}_{\mathrm{STP}^{3}} \mathrm{~kg}_{\mathrm{cat}}{ }^{-1} \mathrm{~h}^{-1}$. Co loadings are about $20 \mathrm{wt}$ $\%{ }^{46}$ Reproduced with permission from Wiley-VCH Verlag GmbH \& Co. 
functionality and, consequently, alter the product selectivity. ${ }^{38}$ This parameter correlates with the extent of aromatic formation in the course of reaction. Botes et al. ${ }^{57,58}$ compared two H-ZSM-5 zeolites with different Si/Al ratios (15 and 140) when combined with Fe-based catalysts in 1BED and 2BED configurations. Although initially higher, the aromatic fraction produced over the high-acidity zeolite sharply decreased and dropped below that produced over the low-acidity one. Therefore, the low-acidity zeolite showed a more stable behavior and produced a higher fraction of aromatics after $150 \mathrm{~h}$ TOS. This conclusion on H-ZSM-5 is confirmed by others as well. ${ }^{52,92}$ In general $\mathrm{H}-\mathrm{ZSM}-5$ is fairly resistant towards coke formation due to its narrow channel type structure and well distributed acid sites. FTS reaction results confirm that H-ZSM-5-containing 1BED systems are more stable and selective to branched hydrocarbons than mixed catalysts containing other zeolite topologies including MCM-22, ITQ-2, ITQ-22, IM-5, USY, H-Beta, and H-MOR. ${ }^{38,51,87}$ The lifetime can considerably be improved by decreasing the zeolite crystallite size, allowing a better utilization of the zeolite microporosity, due to shorter diffusion distances. Another approach frequently reported is adding Pd as a (de)hydrogenation function. ${ }^{51,52,92}$

$\mathrm{Up}$ to $250 \mathrm{~h}$ on-stream at $553 \mathrm{~K}$, the isomer selectivity drops by less than $25 \%$ of its corresponding value at $50 \mathrm{~h}$ TOS over H-ZSM-5 $(\mathrm{Si} / \mathrm{Al}=140) .{ }^{92}$ However, the decrease in production of $\mathrm{C} 4$ isomers is more than $50 \%$ of its initial value after ca. $200 \mathrm{~h}$ on-stream at $573 \mathrm{~K}(\mathrm{H}-\mathrm{ZSM}-5, \mathrm{Si} / \mathrm{Al}=25) \cdot{ }^{56}$ FTS rate was relatively stable over the Fe component under these conditions. Reactivation at $573 \mathrm{~K}$ in an $\mathrm{O}_{2}$ containing environment is not sufficient to regenerate the H-ZSM-5 zeolite $(\mathrm{Si} / \mathrm{Al}=14)$ while the $\mathrm{Fe}$ component is totally reactivated after reduction. ${ }^{114}$ As expected, coke formation is amplified over the zeolite at HTFT conditions, where the reaction temperatures are higher than $573 \mathrm{~K}$. One the other hand, many reports suggest a more stable performance of the acid function at LTFT conditions. ${ }^{6,41,46,98,103,107}$ Recently, a $7.5 \mathrm{wt} \%$ Co-0.2 wt\% Ru-catalyst, supported on alumina bound ZSM-5, is reported to show a stable performance and high selectivity to C5-C20 up to $1500 \mathrm{~h}$ on-stream at $493 \mathrm{~K}^{6}{ }^{\text {After }}$ $140 \mathrm{~h}$ on-stream at $513 \mathrm{~K}$, reactivation of Co/mesoH-ZSM-5 by $\mathrm{H}_{2}$ at $773 \mathrm{~K}$ results in the recovery of the initial iso- to $n$-C4 product ratio over this catalyst along with its initial FTS activity. ${ }^{46}$ This suggests that H-ZSM-5 framework does not collapse under LTFT conditions, although lowered intensity of MFI diffraction patterns are reported for spent catalysts as compared with the fresh ones. ${ }^{50}$

\section{Conclusions}

The combination of zeolites with an active FTS phase increases the product selectivity towards liquid hydrocarbons. This approach offers a great potential for intensified and direct production of synthetic fuels from syngas. Among different zeolite topologies, the most promising results are obtained with H-ZSM-5. The main advantages of the use of this zeolite in combination with FTS functionalities are: (i) it is one of the few zeolites industrially produced and applied for acid-catalyzed hydrocarbon conversion reactions, (ii) it has a (relatively) stable catalytic performance, especially at LTFT process conditions, and (iii) besides acid-catalyzed cracking, it has a fair isomerization and oligomerization activity at low temperatures. The latter oligomerization initiates the hydrocracking reaction via a bimolecular mechanism, since olefins are primary FTS products.

Although HTFT conditions are, in principle, more compatible with hydrocracking and other acid-catalyzed reactions than LTFT conditions, acid sites deactivate relatively fast due to coke formation during HTFT. Therefore, such an integration of different functions seems to be more feasible at LTFT conditions, making Co the desired FTS phase.

In most literature examples, the combination of Co based FTS catalyst and zeolitic acidity results in high selectivities towards gasoline range hydrocarbons. This is mostly due to the type and mechanisms of acid-catalyzed reactions over zeolites in bifunctional systems (Fig. 14). While oligomerization decreases the amount of lower olefins, cracking of the reactive large hydrocarbons breaks the conventional ASF product selectivity at higher carbon numbers. Both reactions will produce branched hydrocarbons. Small branched hydrocarbons do not participate in the FTS chain propagation effectively and, at the same time, larger hydrocarbons will be get trapped in the narrow zeolite channels (such as those of H-ZSM-5) where they undergo excessive isomerization and cracking. In this sense, the use of larger pore zeolites, acidic enough as to display cracking activity under FTS conditions, would be ideal for the production of longer hydrocarbons, in the diesel fuel range.

A crucial factor affecting the product selectivity of bifunctional catalysts is the proximity between acid and FTS components. The closer the sites the more olefinic products reach acid sites before undergoing hydrogenation. This fact makes zeolite supported Co catalysts the best performing ones among the different options in terms of active site proximity. However, in spite of these advantages, a number of drawbacks need to be addressed in order to make the direct synthesis of liquid hydrocarbons from syngas more attractive, namely:

(i) the high selectivity towards methane derived from the strong interactions between the FTS phase and the zeolite. This is a great catalyst synthesis challenge related to the state of the FTS metal particles, since reducibility, size, interactions with the zeolite, coordination of metal atoms, etc. directly affects the FTS chain growth. In many occasions, approaches including hydrothermal synthesis to form a zeolite coating around the metal (agglomerates) or impregnation of the FTS functionality with zeolitic supports, led to lower chain growth probabilities and/or promotion of side reactions (e.g., CO hydrogenation and hydrocarbon hydrogenolysis).

(ii) the long-term stability of these catalysts has been largely unexplored. Future studies should certainly address this point and demonstrate that the lifetime of the 


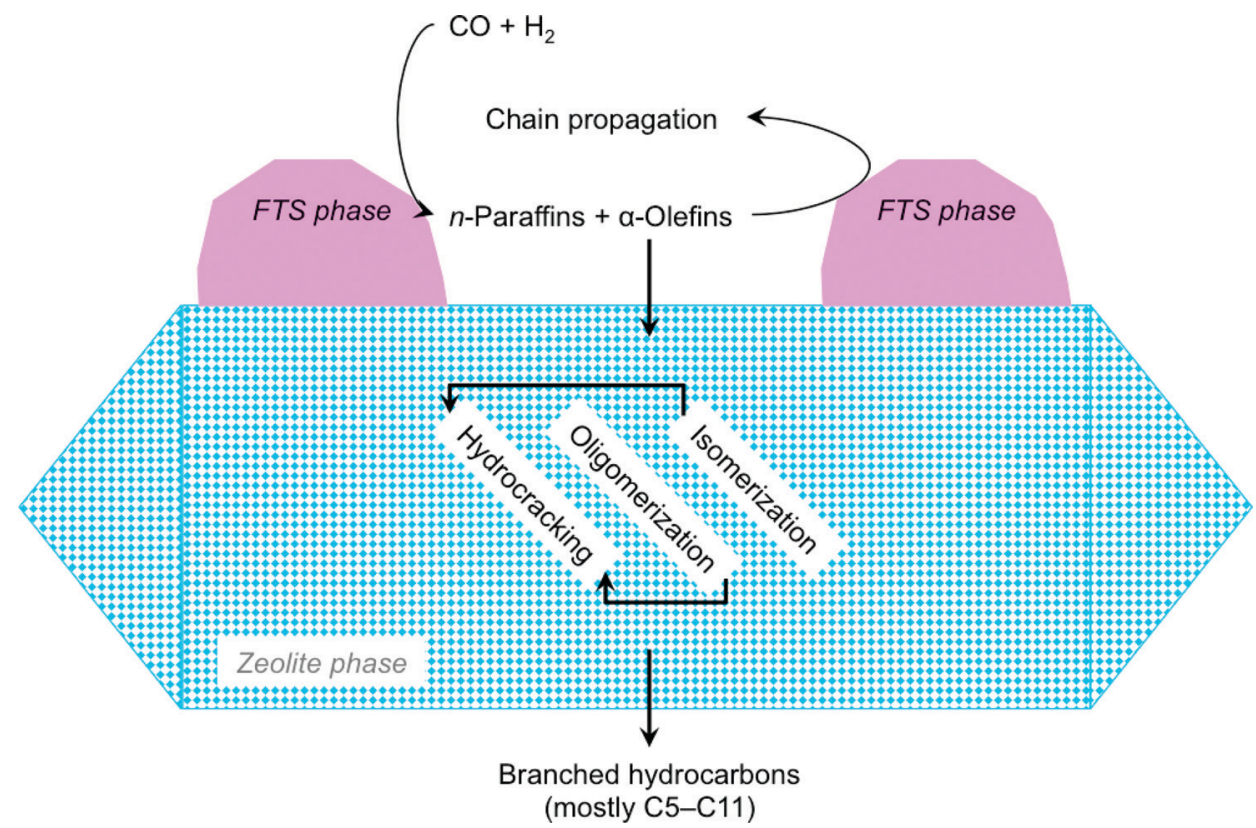

Fig. 14 Schematic representation of reactions involved in zeolite-containing FTS catalysts.

zeolite containing catalysts is comparable to that of other FTS catalysts.

\section{References}

1 S. T. Sie, M. M. G. Senden and H. M. H. Van Wechem, Catal. Today, 1991, 8, 371-394.

2 A. de Klerk and E. Furimsky, Catalysis in the Refining of Fischer-Tropsch Syncrude, RSC Publishing, Cambridge, UK, 2010.

3 M. J. A. Tijmensen, A. P. C. Faaij, C. N. Hamelinck and M. R. M. Van Hardeveld, Biomass Bioenergy, 2002, 23, 129-152.

4 http://www.compactgtl.com/.

5 http://www.velocys.com/.

6 C. Kibby, K. Jothimurugesan, T. Das, H. S. Lacheen, T. Rea and R. J. Saxton, Catal. Today, 2013, 215, 131-141.

7 Q. Zhang, K. Cheng, J. Kang, W. Deng and Y. Wang, ChemSusChem, 2014, DOI: 10.1002/cssc.201300797.

8 V. U. S. Rao, R. J. Gormley, A. Shamsi, T. R. Petrick, J. M. Stencel, R. R. Schehl, R. D. H. Chi and R. T. Obermyer, J. Mol. Catal., 1985, 29, 271-283.

9 V. Udaya, S. Rao and R. J. Gormley, Catal. Today, 1990, 6, 207-234.

10 C. A. Chanenchuk, I. C. Yates and C. N. Satterfield, Energy Fuels, 1991, 5, 847-855.

11 D. Vervloet, F. Kapteijn, J. Nijenhuis and J. R. Van Ommen, Catal. Sci. Technol., 2012, 2, 1221-1233.

12 O. O. James, A. M. Mesubi, T. C. Ako and S. Maity, Fuel Process. Technol., 2010, 91, 136-144.

13 C. Zeng, J. Sun, G. Yang, I. Ooki, K. Hayashi, Y. Yoneyama, A. Taguchi, T. Abe and N. Tsubaki, Fuel, 2013, 112, 140-144.
14 M. E. Dry, Catal. Today, 2002, 71, 227-241.

15 A. Y. Khodakov, W. Chu and P. Fongarland, Chem. Rev., 2007, 107, 1692-1744.

16 A. Martínez and G. Prieto, Top. Catal., 2008, 52, 75-90.

17 Q. Zhang, J. Kang and Y. Wang, ChemCatChem, 2010, 2, 1030-1058.

18 S. Abelló and D. Montané, ChemSusChem, 2011, 4, 1538-1556.

19 E. F. Sousa-Aguiar, F. B. Noronha and A. Faro, Catal. Sci. Technol., 2011, 1, 698-713.

20 B. Sun, M. Qiao, K. Fan, J. Ulrich and F. F. Tao, ChemCatChem, 2011, 3, 542-550.

21 J. D. Roberts, C. C. Lee and W. H. Saunders Jr, J. Am. Chem. Soc., 1954, 76, 4501-4510.

22 M. Rigutto, in Zeolites and Catalysis: Synthesis, Reactions and Applications, ed. J. Čejka, A. Corma and S. Zones, WILEY-VCH Verlag GmbH \& Co. KGaA, Weinheim, 2010, vol. 2, ch. 18, pp. 547-584.

23 S. T. Sie, Ind. Eng. Chem. Res., 1992, 31, 1881-1889.

24 J. Weitkamp, P. A. Jacobs and J. A. Martens, Appl. Catal., 1983, 8, 123-141.

25 A. Soualah, J. L. Lemberton, L. Pinard, M. Chater, P. Magnoux and K. Moljord, Appl. Catal., A, 2008, 336, 23-28.

26 M. J. G. Janssen, W. J. Mortier, C. W. M. van Oorschot and M. Makkee, Process for catalytic conversion of olefins, WO 91/18851, 1991.

27 G. D. Pirngruber, O. P. E. Zinck-Stagno, K. Seshan and J. A. Lercher, J. Catal., 2000, 190, 374-386.

28 F. Bauer, E. Bilz, W. H. Chen, A. Freyer, V. Sauerland and S. B. Liu, Isomerization of n-butene over pre-coked HZSM-5 and HFER, 2007, vol. 170, pp. 1096-1103.

29 M. Guisnet, P. Andy, N. S. Gnep, E. Benazzi and C. Travers, J. Catal., 1996, 158, 551-560. 
30 P. Meriaudeau, R. Bacaud, L. Ngoc Hung and A. T. Vu, J. Mol. Catal. A: Chem., 1996, 110, L177-L179.

31 K. A. Cumming and B. W. Wojciechowski, Catal. Rev. Sci. Eng., 1996, 38, 101-157.

32 A. Corma, J. Planelles, J. Sánchez-Marín and F. Tomás, J. Catal., 1985, 93, 30-37.

33 X. Dupain, R. A. Krul, C. J. Schaverien, M. Makkee and J. A. Moulijn, Appl. Catal., B, 2006, 63, 277-295.

34 T. V. Malleswara Rao, X. Dupain and M. Makkee, Microporous Mesoporous Mater., 2012, 164, 148-163.

35 C. Bouchy, G. Hastoy, E. Guillon and J. A. Martens, Oil Gas Sci. Technol., 2009, 64, 91-112.

36 D. Leckel, Energy Fuels, 2007, 21, 1425-1431.

37 A. V. Abramova, A. A. Panin, G. A. Kliger, E. A. Kulikova and E. V. Slivinsky, Stud. Surf. Sci. Catal., 2005, 158, 1709-1716.

38 A. Martínez, J. Rollán, M. A. Arribas, H. S. Cerqueira, A. F. Costa and E. F. S.-Aguiar, J. Catal., 2007, 249, 162-173.

39 A. Mena Subiranas and G. Schaub, Int. J. Chem. React. Eng., 2007, 5, A78.

40 A. Mena Subiranas and G. Schaub, Int. J. Chem. React. Eng., 2009, 7, A31.

41 A. Freitez, K. Pabst, B. Kraushaar-Czarnetzki and G. Schaub, Ind. Eng. Chem. Res., 2011, 50, 13732-13741.

42 J. Kang, K. Cheng, L. Zhang, Q. Zhang, J. Ding, W. Hua, Y. Lou, Q. Zhai and Y. Wang, Angew. Chem., Int. Ed., 2011, 50, 5200-5203.

43 S. Sartipi, M. Alberts, M. J. Meijerink, T. C. Keller, J. Pérez-Ramírez, J. Gascon and F. Kapteijn, ChemSusChem, 2013, 6, 1646-1650.

44 S. Sartipi, K. Parashar, M. J. Valero-Romero, V. P. Santos, B. Van Der Linden, M. Makkee, F. Kapteijn and J. Gascon, J. Catal., 2013, 305, 179-190.

45 W. Böhringer, A. Kotsiopoulos, M. de Boer, C. Knottenbelt and J. C. Q. Fletcher, Selective Fischer-Tropsch wax hydrocracking - opportunity for improvement of overall gas-toliquids processing, 2007, vol. 163, pp. 345-365.

46 S. Sartipi, M. Alberts, V. P. Santos, M. Nasalevich, J. Gascon and F. Kapteijn, ChemCatChem, 2014, 6, 142.

47 S. Sartipi, K. Parashar, M. Makkee, J. Gascon and F. Kapteijn, Catal. Sci. Technol., 2013, 3, 572-575.

48 N. Tsubaki, Y. Yoneyama, K. Michiki and K. Fujimoto, Catal. Commun., 2003, 4, 108-111.

49 Y. Jin, R. Yang, Y. Mori, J. Sun, A. Taguchi, Y. Yoneyama, T. Abe and N. Tsubaki, Appl. Catal., A, 2013, 456, 75-81.

50 S. H. Kang, J. W. Bae, P. S. S. Prasad and K. W. Jun, Catal. Lett., 2008, 125, 264-270.

51 A. Martínez, C. López, E. Peris and A. Corma, In situ transformation of Fischer-Tropsch products into high-octane gasoline-range hydrocarbons by using hybrid zeolite-based catalysts, 2005, vol. 158 B, pp. 1327-1334.

52 A. Martínez and C. López, Appl. Catal., A, 2005, 294, 251-259.

53 J. Wei, Ind. Eng. Chem. Res., 1994, 33, 2467-2472.

54 K. Jothimurugesan and S. K. Gangwal, Ind. Eng. Chem. Res., 1998, 37, 1181-1188.

55 A. N. Pour, M. Zare, S. M. Kamali Shahri, Y. Zamani and M. R. Alaei, J. Nat. Gas Sci. Eng., 2009, 1, 183-189.
56 A. V. Karre, A. Kababji, E. L. Kugler and D. B. Dadyburjor, Catal. Today, 2013, 214, 82-89.

57 F. G. Botes and W. Böhringer, Appl. Catal., A, 2004, 267, 217-225.

58 F. G. Botes, Appl. Catal., A, 2005, 284, 21-29.

59 A. V. Karre, A. Kababji, E. L. Kugler and D. B. Dadyburjor, Catal. Today, 2012, 198, 280-288.

60 H. M. T. Galvis, J. H. Bitter, C. B. Khare, M. Ruitenbeek, A. I. Dugulan and K. P. de Jong, Science, 2012, 335, 835-838.

61 I. C. Yates and C. N. Satterfield, Energy Fuels, 1992, 6, 308-314.

62 H. Schulz, Comparing Fischer-Tropsch synthesis on iron- and cobalt catalysts. The dynamics of structure and function, 2007, vol. 163, pp. 177-199.

63 G. L. Bezemer, J. H. Bitter, H. P. C. E. Kuipers, H. Oosterbeek, J. E. Holewijn, X. Xu, F. Kapteijn, A. J. Van Diilen and K. P. De Jong, J. Am. Chem. Soc., 2006, 128, 3956-3964.

64 R. Van Hardeveld and F. Hartog, Surf. Sci., 1969, 15, 189-230.

65 J. P. Den Breejen, P. B. Radstake, G. L. Bezemer, J. H. Bitter, V. Frøseth, A. Holmen and K. P. De Jong, J. Am. Chem. Soc., 2009, 131, 7197-7203.

66 H. M. Torres Galvis, J. H. Bitter, T. Davidian, M. Ruitenbeek, A. I. Dugulan and K. P. De Jong, J. Am. Chem. Soc., 2012, 134, 16207-16215.

67 G. Blyholder, J. Phys. Chem., 1964, 68, 2772-2778.

68 G. Blyholder and L. D. Neff, J. Phys. Chem., 1969, 73, 3494-3496.

69 L. E. S. Rygh and C. J. Nielsen, J. Catal., 2000, 194, 401-409.

70 P. Wang, J. Kang, Q. Zhang and Y. Wang, Catal. Lett., 2007, 114, 178-184.

71 B. Sun, G. Yu, J. Lin, K. Xu, Y. Pei, S. Yan, M. Qiao, K. Fan, X. Zhang and B. Zong, Catal. Sci. Technol., 2012, 2, 1625-1629.

72 G. Maire and F. Garin, J. Mol. Catal., 1988, 48, 99-116.

73 A. Cimino, M. Boudart and H. Taylor, J. Phys. Chem., 1954, 58, 796-800.

74 J. H. Sinfelt, Catal. Rev., 1970, 3, 175-205.

75 J. H. Sinfelt, Catal. Lett., 1991, 9, 159-171.

76 J. H. Sinfelt, Specificity in Catalytic Hydrogenolysis by Metals, 1973, vol. 23, pp. 91-119.

77 R. J. Gormley, V. U. S. Rao, R. R. Anderson, R. R. Schehl and R. D. H. Chi, J. Catal., 1988, 113, 193-205.

78 C. J. Machiels and R. B. Anderson, J. Catal., 1979, 58, 253-259.

79 J. L. Carter, J. A. Cusumano and J. H. Sinfelt, J. Catal., 1971, 20, 223-229.

80 J. R. Anderson and N. R. Avery, J. Catal., 1967, 7, 315-323.

81 H. Matsumoto, Y. Saito and Y. Yoneda, J. Catal., 1970, 19, 101-112.

82 Y. Barron, G. Maire, J. M. Muller and F. G. Gault, J. Catal., 1966, 5, 428-445.

83 V. Ponec and G. C. Bond, Catalysis by Metals and Alloys, 1995, ch. 6, vol. 95, pp. 247-297.

84 J. A. Moulijn, J. Perez-Ramirez, A. van Diepen, M. T. Kreutzer and F. Kapteijn, Int. J. Chem. React. Eng., 2003, 1, R4. 
85 T. S. Zhao, J. Chang, Y. Yoneyama and N. Tsubaki, Ind. Eng. Chem. Res., 2005, 44, 769-775.

86 I. Nam, K. M. Cho, J. G. Seo, S. Hwang, K. W. Jun and I. K. Song, Catal. Lett., 2009, 130, 192-197.

87 A. Martínez, S. Valencia, R. Murciano, H. S. Cerqueira, A. F. Costa and E. F. S.-Aguiar, Appl. Catal., A, 2008, 346, 117-125.

88 J. Y. Liu, J. F. Chen and Y. Zhang, Catal. Sci. Technol., 2013, 3, 2559-2564.

89 S. Sartipi, J. van Dijk, J. Gascon and F. Kapteijn, Appl. Catal., A, 2013, 456, 11-22.

90 G. Yang, C. Xing, W. Hirohama, Y. Jin, C. Zeng, Y. Suehiro, T. Wang, Y. Yoneyama and N. Tsubaki, Catal. Today, 2013, 215, 29-35.

91 K. Cheng, J. Kang, S. Huang, Z. You, Q. Zhang, J. Ding, W. Hua, Y. Lou, W. Deng and Y. Wang, ACS Catal., 2012, 2, 441-449.

92 M. Baranak, B. Gürünlü, A. Sarioğlan, Ö. Ataç and H. Atakül, Catal. Today, 2013, 207, 57-64.

93 J. Bao, G. Yang, C. Okada, Y. Yoneyama and N. Tsubaki, Appl. Catal., A, 2011, 394, 195-200.

94 J. He, B. Xu, Y. Yoneyama, N. Nishiyama and N. Tsubaki, Chem. Lett., 2005, 34, 148-149.

95 J. He, Y. Yoneyama, B. Xu, N. Nishiyama and N. Tsubaki, Langmuir, 2005, 21, 1699-1702.

96 N. Nishiyama, K. Ichioka, D. H. Park, Y. Egashira, K. Ueyama, L. Gora, W. Zhu, F. Kapteijn and J. A. Moulijn, Ind. Eng. Chem. Res., 2004, 43, 1211-1215.

97 N. Nishiyama, K. Ichioka, M. Miyamoto, Y. Egashira, K. Ueyama, L. Gora, W. Zhu, F. Kapteijn and J. A. Moulijn, Microporous Mesoporous Mater., 2005, 83, 244-250.

98 J. He, Z. Liu, Y. Yoneyama, N. Nishiyama and N. Tsubaki, Chem.-Eur. J., 2006, 12, 8296-8304.

99 G. Yang, J. He, Y. Yoneyama, Y. Tan, Y. Han and N. Tsubaki, Appl. Catal., A, 2007, 329, 99-105.
100 G. Yang, J. He, Y. Yoneyama and N. Tsubaki, H-ZSM-5/ cobalt/silica capsule catalysts with different crystallization time for direct synthesis of isoparaffins: simultaneous realization of space confinement effect and shape selectivity effect, 2007, vol. 167, pp. 73-78.

101 J. Bao, J. He, Y. Zhang, Y. Yoneyama and N. Tsubaki, Angew. Chem., Int. Ed., 2008, 47, 353-356.

102 G. Yang, J. He, Y. Yoneyama, Y. Tan, Y. Han and N. Tsubaki, Res. Chem. Intermed., 2008, 34, 771-779.

103 G. Yang, J. He, Y. Zhang, Y. Yoneyama, Y. Tan, Y. Han, T. Vitidsant and N. Tsubaki, Energy Fuels, 2008, 22, 1463-1468.

104 G. Yang, Y. Tan, Y. Han, J. Qiu and N. Tsubaki, Catal. Commun., 2008, 9, 2520-2524.

105 X. Li, J. He, M. Meng, Y. Yoneyama and N. Tsubaki, J. Catal., 2009, 265, 26-34.

106 M. Thongkam, G. Yang, T. Vitidsant and N. Tsubaki, J. Jpn. Pet. Inst., 2009, 52, 216-217.

107 X. Huang, B. Hou, J. Wang, D. Li, L. Jia, J. Chen and Y. Sun, Appl. Catal., A, 2011, 408, 38-46.

108 N. Jiang, G. Yang, X. Zhang, L. Wang, C. Shi and N. Tsubaki, Catal. Commun., 2011, 12, 951-954.

109 S. H. Kang, J. H. Ryu, J. H. Kim, I. H. Jang, A. R. Kim, G. Y. Han, J. W. Bae and K. S. Ha, Energy Fuels, 2012, 26, 6061-6069.

110 C. Li, H. Xu, Y. Kido, Y. Yoneyama, Y. Suehiro and N. Tsubaki, ChemSusChem, 2012, 5, 862-866.

111 F. Kapteijn and J. A. Moulijn, in Handbook of Heterogeneous Catalysis, Wiley-VCH Verlag GmbH \& Co. KGaA, 2008.

112 C. Ngamcharussrivichai, A. Imyim, X. Li and K. Fujimoto, Ind. Eng. Chem. Res., 2007, 46, 6883-6890.

113 S. Mitchell, N. L. Michels, K. Kunze and J. Pérez-Ramírez, Nat. Chem., 2012, 4, 825-831.

114 A. Nakhaei Pour and M. R. Housaindokht, J. Nat. Gas Sci. Eng., 2013, 14, 49-54. 